Florida International University FIU Digital Commons

FIU Electronic Theses and Dissertations

University Graduate School

$11-13-2013$

\title{
Soil Building Processes in Reconstructed Tree Islands in The Everglades, Florida
}

Andres F. Rodriguez

Florida International University, arodr760@fiu.edu

DOI: $10.25148 /$ etd.FI13120612

Follow this and additional works at: https://digitalcommons.fiu.edu/etd

Part of the Biogeochemistry Commons, Environmental Sciences Commons, and the Soil Science Commons

\section{Recommended Citation}

Rodriguez, Andres F., "Soil Building Processes in Reconstructed Tree Islands in The Everglades, Florida" (2013). FIU Electronic Theses and Dissertations. 1021.

https://digitalcommons.fiu.edu/etd/1021

This work is brought to you for free and open access by the University Graduate School at FIU Digital Commons. It has been accepted for inclusion in FIU Electronic Theses and Dissertations by an authorized administrator of FIU Digital Commons. For more information, please contact dcc@fiu.edu. 


\section{FLORIDA INTERNATIONAL UNIVERSITY}

Miami, Florida

\section{SOIL BUILDING PROCESSES IN RECONSTRUCTED TREE ISLANDS IN THE EVERGLADES, FLORIDA}

A thesis submitted in partial fulfillment of

the requirements for the degree of

MASTER OF SCIENCE

in

ENVIRONMENTAL STUDIES

by

Andres F. Rodriguez 
To: Dean Kenneth G. Furton

College of Arts and Sciences

This thesis, written by, Andres F. Rodriguez and entitled, Soil Building Processes in Reconstructed Tree Islands in The Everglades, Florida having been approved in respect to style and intellectual content, is referred to you for judgment.

We have read this thesis and recommend that it be approved.

Krishnaswamy Jayachandran

Michael Ross

Leonard J. Scinto, Major Professor

Date of Defense: November 13, 2013.

The thesis of Andres F. Rodriguez is approved.

Dean Kenneth G. Furton
College of Arts and Sciences

Dean Lakshmi N. Reddi

University Graduate School

Florida International University, 2013 


\section{ACKNOWLEDGMENTS}

I would like to express my gratitude to the Freshwater Biogeochemistry Laboratory at Florida International University, the Southeast Environmental Research Center at Florida International University, and the department of Earth and Environment at Florida International University for their help and support during the development of this project. 
ABSTRACT OF THE THESIS

SOIL BUILDING PROCESSES IN RECONSTRUCTED TREE ISLANDS IN THE EVERGLADES, FLORIDA

\author{
by
}

Andres F. Rodriguez

Florida International University, 2013

Miami, Florida

\title{
Professor Leonard J. Scinto, Major Professor
}

Soil building processes were studied in reconstructed tree islands in the Loxahatchee Impoundment Landscape Assessment, Florida. Soil building was evaluated by measuring litter production, litter decomposition, soil accretion, and changes in soil elevation under different hydrologic conditions, and by determining physicochemical characteristics of newly accreted soils. Tree islands showed higher litter production and soil accretion but a larger loss of soil elevation caused by subsidence at higher elevations and shorter inundation periods. Newly accreted soils exhibited higher nutrient concentrations, and organic matter (OM) than older soils. Most of the soil phosphorus was stored in the organic fraction. A positive correlation was found between soil nutrients and OM. Reconstructed tree islands are increasing in soil OM and nutrients, generating a positive feedback that increases tree productivity, and soil building. These findings contribute to the understanding of tree islands' dynamics and can be used by managers for restoration efforts in the Everglades. 


\section{TABLE OF CONTENTS}

CHAPTER

PAGE

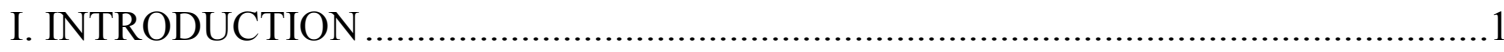

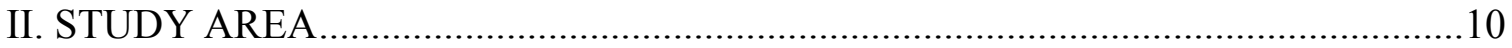

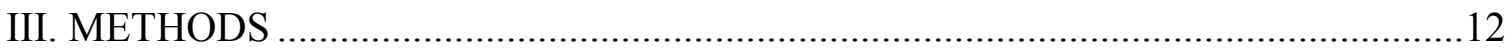

Statistical analysis ........................................................................................

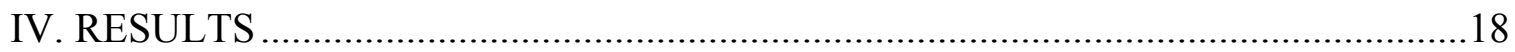

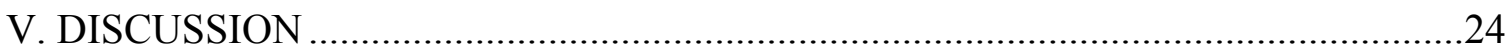

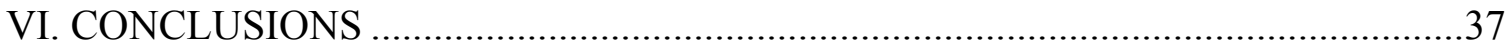

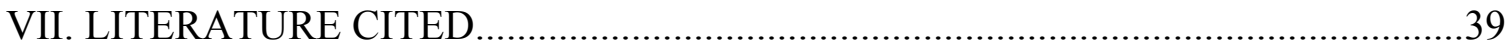

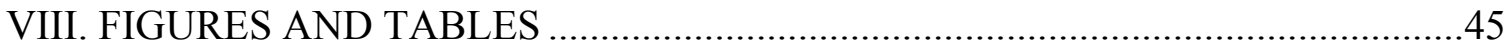




\section{LIST OF FIGURES}

FIGURE

PAGE

1. Total phosphorus concentrations in different sections of a tree island and in the surrounding mash. Concentrations are in $\mu \mathrm{g} \mathrm{g}^{-1}$. Image from Wetzel et al., 2005. .45

2. Peat equilibrium elevation relative to decomposition rates. Figure from Larsen et al., 2011

3. Diagram showing the location and components of LILA macrocosms, modified from Aich et al., 2011

4. Cross section of a LILA macrocosm with all features and their correspondent elevations

5. LILA operational hydrograph

6. Diagram showing a detail of four planting densities in M4W (dots represent trees of different species)

7. Aerial photograph of a LILA tree island showing the sections within the tree island, and the location of the experiments. LICOR experiment is not part of this study.

8. Figure 8 Hydrograph showing water levels for the four LILA macrocosms, and average elevation of the head high and head low plots from April 2009 to August 2012. Dashed lines correspond to $1 \mathrm{SD}$ for the head low plots.

9. Measurement of accretion using a feldspar marker. The amount of accreted soil is on top of the feldspar white layer.

10. Measurement of soil elevation using a surface elevation table (SET) in one of LILA tree islands at the high elevation in the highest density planting..................... 50

11. Diagram showing an example of shallow subsidence calculation by using accretion and changes in soil elevation.

12. Mean ( $\pm 1 \mathrm{SD})$ leaf litter collected in the four western tree island heads at high $(\mathrm{HH})$ and low (HL) elevations, in the highest density planting with $1 \mathrm{~m}$ spacing between trees from September 2010 to July 2012. Figure shows year of plantation of each tree islands.

13. Litter collected at the highest density planting ( $1 \mathrm{~m}$ space between trees) in the four western tree islands combined (only in the head high locations) for different substrates from September 2010 to July 2012). 
14. Decomposition expressed as percentage remaining litter mass after $732 \mathrm{~d}(24 \mathrm{mo})$ of decomposition in the western tree islands at high $(\mathrm{HH})$ and low $(\mathrm{HL})$ elevations.

Decomposition constants $\mathrm{k}(\mathrm{d}-1)$ are based on an exponential decomposition model [Mt $=$ $\mathrm{M} 0 \mathrm{e}-\mathrm{kt}$, where $\mathrm{Mt}$ is the mass remaining at time $\mathrm{t}$ and $\mathrm{M} 0$ is the initial mass] and $\mathrm{r} 2$ from regression analysis. Values are mean \pm 1 SD from triplicate bags $(n=3)$.

Percentages of mass loss after $732 \mathrm{~d}$ ( $24 \mathrm{mo})$ of decomposition are also showed.

15. Soil accreting one (2010), two (2011), and three (2012) years after 2009 initial measurements above feldspar markers located at high (Head High, HH) and low elevations (Head Low) at the heads of eight tree islands combined.

16. Surface elevation table (SET) elevation differences one (2010), two (2011), and three (2012) years after 2009 initial measurements at high (Head High) and low elevation (Head Low) of heads of eight tree islands combined.

17. Surface elevation table (SET) elevation differences one (2010), two (2011), and three (2012) years after 2009 initial measurements at high (Head High) and low elevation (Head Low) of heads of eight tree islands combined.

18. Surface elevation table (SET) elevation differences between 2009 initial measurements and subsequent years 2010, 2011 and 2012 data $(n=8)$ at mid-slope (Tail High, TH) and at the base of the tail slope (Tail Low, TL) of eight tree islands combined.

19. Total phosphorus concentrations for combinations of soil depth and planting density. All islands combined, all elevations combined. Letters correspond to groups according to Tukey HSD Post Hoc comparisons................................................ 57

20. Concentration of $P$ fractions for two soil increments top $(0-3 \mathrm{~cm})$, and bottom $(3-10$ $\mathrm{cm}) . \mathrm{n}=48$. Values are means $+/-\mathrm{SD}$. $\mathrm{p}$ values correspond to independent samples $\mathrm{t}$-tests between soil increments.

21. Available phosphorus concentration for combinations of soil depth and planting density. All islands combined, all elevations combined. Letters correspond to groups according to Dunnett C Post Hoc comparisons. 


\section{LIST OF TABLES}

TABLE

PAGE

1. Rates of annual litter production estimated from litter traps at high and low elevations, $\mathrm{n}=24$, and peat and limestone substrates, $\mathrm{n}=12$.

2. Rates of accretion, change in elevation, and shallow subsidence for high and low elevation at the head of all eight tree islands, $n=8$.

3. Pearson correlation for soil characteristics using two increments and all islands combined, $\mathrm{n}=95$.

4. Independent samples t tests results for soils separated in two soil increments, all four islands, and both planting densities combined. Values are means $+/-\operatorname{SD} .(n=48)$.

5. Independent samples $t$ tests results for top soils $(0-3 \mathrm{~cm})$ separated in high and low elevations, only in peat substrate, both planting densities combined. Values are means $+/-$ SD. High elevation $n=12$, low elevation $n=24$.

6. Independent samples $T$ tests results for top soils $(0-3 \mathrm{~cm})$ separated in limestone and peat substrates only in high elevations, both planting densities combined. Values are means + - SD., $\mathrm{n}=12$.

7. Independent samples $\mathrm{T}$ tests results for top soils separated in planting densities, both elevations combined. Values are means $+/-$ SD., $n=24$.

8. Independent samples t tests results comparing soil characteristics for $0-10 \mathrm{~cm}$ cores. Values are mean $+/-$ SD. Substrate was evaluated only at high elevations $(n=12)$, elevation was evaluated only in peat substrate $(n=12$ for high, and 23 for low), $n=24$ for planting density. 


\section{INTRODUCTION}

The Everglades are located at the southern end of the peninsula of Florida in the southeastern United States. They occupy an area of $28490 \mathrm{~m}^{2}$, have an average rainfall of $157 \mathrm{~cm} \mathrm{yr}^{-1}$, and are exposed to wet season hurricanes and dry season fires (Perry, 2004). The Everglades wet season takes place between May and October, and the dry season between November and April (Wetzel et al., 2005). The deepest water levels lag behind the precipitation pattern with highest from September to January, and the lowest from April to June. The average temperatures range in the mid $20{ }^{\circ} \mathrm{C}$ with lows in the winter averaging $15^{\circ} \mathrm{C}$ and highs in summer of about $27^{\circ} \mathrm{C}$ (Brown et al., 2006). Differences in soil building processes within the Everglades produce different landscape features, and increase the heterogeneity of the ecosystem.

The Everglades are referred to as a meta-ecosystem with differentiated ecosystem components (Wetzel et al., 2005), meaning that it is a big ecosystem composed of subsystems that act and interact in an independent way. The natural landscape of the Everglades is composed by large peat ridges dominated by sawgrass, lower and more open peat sloughs, dominated by water lilies, and teardrop or cigar-shaped tree islands which contain a diverse assemblage of trees, shrubs and ferns (Larsen et al., 2011). The rapid precipitation of phosphorus bounded compounds like $\mathrm{Ca}-\mathrm{P}, \mathrm{Mg}-\mathrm{P}, \mathrm{Al}-\mathrm{P}, \mathrm{Fe}-\mathrm{P}$ or $\mathrm{PO}_{4}$ compounds that takes place when $\mathrm{P}$ is intercepted by periphyton, make the Everglades a P limited ecosystem (Wetzel et al., 2005 ). 
Everglades tree islands range in area from $10 \mathrm{~m}^{2}$ to 70 ha, and typically have elevations from 20 to $100 \mathrm{~cm}$ above the surrounding marsh (Wetzel et al., 2005). Different sections within tree islands experience different periods of inundation (hydroperiods). The head of tree islands which is located upstream, and has a well defined canopy, has the highest soil elevation, and is permanently above water. The tail, located downstream, with an open canopy, experiences long floods because of its lower soil elevation (Bazante et al., 2006). These two sections (head, and tail) within tree islands, have different soil dynamics because of the differential influence of hydroperiod.

Hydrology is a determining factor for tree islands. Water levels in tree islands affect vegetation establishment, and characteristics. Plant communities that are flooded longest and deepest support more open canopies, while woody communities less affected by flooding support denser canopies (Ross et al. 2006). Shape and orientation of tree islands are determined by the direction of the flow of water. Bazante et al. (2006) found that vegetation at the head of the tree islands forms channels that transport sediments from the head to the tail where submerged vegetation intercepts them favoring sediment accumulation and elongation of tree islands. Troxler et al. (2006) reported the development of a higher canopy in tree islands under flowing conditions compared to non-flowing tree islands in the southern Everglades. Troxler et al. (2005) found that flowing tree islands have higher litter turnover rates, higher $\mathrm{N}$ concentrations, and lower dissolved organic $\mathrm{C}$ than non-flowing tree islands. Hydrological variations in tree islands help to explain changes in surface water $\mathrm{P}$ and $\mathrm{N}$ concentrations. Phosphorus loading increased through the wet season while $\mathrm{N}$ loading decreased in tree islands located in the 
southern Everglades (Troxler et al., 2005). Troxler and Childers (2009) found that more mass was lost in decomposition experiments with litter in Everglades tree islands under flowing conditions compared to islands with non-flowing conditions. Hydrologic variations affect nutrient concentrations in tree islands soils. Different sections within tree islands exposed to different hydroperiods are expected to exhibit differences in soil characteristics.

An important input to tree island soil organic matter comes from litter produced by plant communities. Troxler et al. (2005) found that Litter production did not have a clear seasonal pattern on tree islands of the southern Everglades, and that species contribution to litterfall varied throughout the year. Litter production in tree islands is controlled by external factors such as temperature (Troxler et al., 2005). Givnish et al. (2008) found that, after hydrological modifications, similar plant communities occupy different levels of water depth and hydroperiod, most likely because communities have not equilibrated yet to recent regional changes in hydrology. Vegetation establishment in slightly elevated surfaces in the Everglades initiates a feedback mechanism by producing litter which returns OM, and nutrients to the soil. These inputs promote the growth of more vegetation, and in time tree islands are formed. Litter production and decomposition are important processes in tree islands' soil development. The influence of hydroperiod in these variables can determine the extent to which plant productivity can promote soil building in tree islands. 
Vegetation exerts a control on nutrient availability in tree islands. Troxler et al., (2005) found dissolved nutrient concentrations and organic C concentrations that reflect low nutrient availability, attributed to high demand in tree islands, caused by trees. Phosphorus availability in tree islands may cause mineralized $\mathrm{N}$ to be taken up more rapidly, decreasing its concentration in the soil (Ross et al., 2006). Declining foliar N:P ratios from the surrounding marsh to the less flooded areas at the head of the tree islands indicate $\mathrm{N}$ limited conditions on tree islands (Ross et al., 2006).

Tree islands are considered a biogeochemical hotspot because of their higher nutrient concentration compared to the surrounding marsh, and high rate of nutrient cycling (Wetzel et al., 2005; Orem et al., 2002). Tree island soil $\mathrm{pH}$ is lower than marsh soil (Troxler et al., 2005). Troxler et al. (2005) found high nutrient use efficiency on highly organic seasonally flooded tree islands, and immobilization of $\mathrm{N}$ and $\mathrm{P}$ taking place on tree islands. Surface water on tree islands contains two times greater total nitrogen (TN) and total organic carbon (TOC) concentrations than marsh sites (Troxler and Childers, 2009). Litter decomposition experiments on nine tree islands in the southern Everglades indicate that $\mathrm{N}$ and $\mathrm{P}$ increase while $\mathrm{C}$ decreases as the litter decomposition process takes place (Troxler and Childers, 2009). A steep gradient exist in soil total phosphorus (TP) concentration from the most flood prone to the least likely to be flooded on tree islands soils, with higher values at the less flooded section (Ross et al., 2006) (Fig. 1), as a consequence, TP concentrations are higher at the head of tree islands and decreases at their tails. Phosphorus concentration in tree islands influence peat accretion directly, through local effects on organic matter production and decomposition 
rates, and indirectly, by exerting control over the composition of the vegetation community and its ability to sequester additional P (Larsen et al., 2011). Tree islands store $\mathrm{P}$ in different fractions, $\mathrm{Ca}$-and $\mathrm{Mg}$-bound $\mathrm{P}$ being the predominant fraction in tree islands in the southern Everglades (Irick et al., 2013). Sequential fractionation procedures define $\mathrm{P}$ extracted with $\mathrm{DDI} \mathrm{H}_{2} \mathrm{O}$ as water soluble $\mathrm{P}$, and $\mathrm{P}$ extracted with $\mathrm{NaCl}$ as available P not solubilized by DDI. These two fractions constitute the available P pool. The $\mathrm{HCl}$ extracted $\mathrm{P}$ is defined as $\mathrm{Ca}$ and $\mathrm{Mg}$ bound $\mathrm{P}$ (Reddy et al., 1998). Differences in hydroperiod within tree islands generate gradients in nutrient concentrations. These nutrient gradients are a distinctive characteristic of tree islands.

Soil accretion in wetland soils is largely controlled by plant communities, and relative soil elevation. Sedimentation rates from autochthonous and allocthonous sources tend to be highest where plant density is greatest and marsh surface elevation is highest (Cahoon and Turner, 1989, Scinto et al., 2013). Roots can increase soil strength and thus new roots should help stabilize storm deposits and slow soil surface erosion (Whelan et al., 2009). Sedimentation could be an important mechanism in tree island formation particularly at the tail of the tree islands where an elongation process takes place.

Soil decomposition processes, and peat accumulation in tree islands depend on vegetation characteristics, and differences in soil elevation. Tree islands have unique peat elevations because of the difference existing between their organic matter production and decomposition curves (Fig. 2), with higher production compared to decomposition in places with higher peat elevation (Larsen et al., 2011). Detrital material with relatively 
high lignin content found in tree island soils decay less rapidly than material found in ridges and sloughs (Debusk and Reddy, 1998). Enhancement of nutrient availability at higher elevations is expected to improve plant production and consequently soil aeration, and sediment accumulation (Ross et al., 2006). Givnish et al. (2008) found evidence indicating a positive relation between plant productivity and the net rate of peat decomposition in slightly elevated surfaces. There is a positive feedback between organic soil accumulation and productivity, the feedback is limited by increased susceptibility to fire during dry periods, and a faster rate of decomposition in higher elevations above the water table, where aerobic conditions are always present (Ross et al. 2006). The factors controlling peat accumulation ultimately control tree islands because peat accumulation is vital for tree islands to achieve the distinctive elevation over the surrounding marsh and allow vegetation establishment.

The marker horizon technique has being extensively used to measure rates of accretion (Cahoon and Turner, 1989; Cahoon et al., 1995; Cahoon et al., 2000; Cahoon and Lynch, 1997; Whelan et al., 2009; Van Dyke, 2012). A marker horizon is a visible layer set into the soil which allows the determination of how much new soil has accreted on top of it in a given period of time. The soil marker horizon method integrates processes such as sediment deposition, erosion, and root growth occurring in the top millimeters or centimeters of the soil (Cahoon 2006).

External factors such as climate events or hydrologic manipulations can affect soil processes in wetlands, disturbing the balance between hydrology and soil that ultimately 
defines wetland ecosystems. The long term growth, stability or decay of coastal wetlands can be responsive to several factors including climatic, and hydrologic both of natural and man-made origin (Cahoon and Turner, 1989). Storm events can increase elevation of wetlands by depositing material, and folding peat layers or can decrease wetland's elevation by eroding sediments, compacting marshes, and collapsing peat by killing the above ground trees (Whelan et al. 2009) (Cahoon, 2006). Day Jr. et al. (1995) found that hydrologically modified deltas in which the influence of pulsing events have been restricted, have relative sea level rise rates higher than the eustatic sea level rise, meaning that these wetlands lose elevation because of subsidence and compaction. Subsurface processes, in many cases caused by external events like storms can affect soil elevation in wetlands. Cahoon (2006) found that subsurface processes dominate most wetland soil elevation responses to storm events. Tree islands of the Everglades are located inland compared to coastal wetlands, however they can also be affected pulsing events that influence hydrology. Under controlled hydrologic conditions, such as the ones present in South Florida, the dominant factors affecting soil elevation in tree islands have to do with the relation between plant communities and hydrology. Changes in soil volume such as compaction, shrink-swell and decomposition can affect the top layers of the soil, and produce changes in elevation (Cahoon et al. 1995; Cahoon, 2006; Cahoon and Lynch, 1997). Compressibility of peat is directly related to organic matter content (Cahoon et al. 1995). Variations on water content of the soil caused either by seasonal variations, human manipulation, storm events, or evapotranspiration can affect soil elevation (Cahoon et al. 1995; Cahoon, 2006; Day Jr. et al. 1995). Changes in soil elevation have been extensively studied in rapidly subsiding areas such as the Mississippi delta. Recreated tree islands in 
the Everglades could also exhibit negative changes in soil elevation generated because of the recent process of construction, and this loss of elevation could jeopardize restoration efforts on tree islands.

Changes in wetland soil elevation have been documented using Surface Elevation Tables (SETs) (Boumans and Day Jr., 1993). In combination with marker horizons SETs can be used to measure shallow subsidence, and accretion rates (Cahoon et al., 1995; Cahoon and Lynch, 1997; Cahoon et al., 2000; Whelan et al., 2009; Van Dyke, 2012). A SET is a portable device designed to attach to a pipe that has been driven into the soil (Cahoon and Lynch, 1997). The Rod SET (RSET) developed by Cahoon et al. (2002) allows to obtain a fixed reference point given by the benchmark pipe to which the arm is attached. The RSET can be located at eight different angles separated by $45^{\circ}$. Its confidence interval varies from \pm 1.3 to $\pm 4.3 \mathrm{~mm}$. with a larger error on flooded surfaces (Cahoon et al., 2002).

Throughout the 20th Century the Everglades have suffered a rapid transformation because of drainage or flooding of selected areas with the objective of guarantee water supply for South Florida's population, and flood protection in the event of tropical storms (Wetzel et al., 2005; Givnish et al., 2008). Changes in hydrology have impacted the ecosystem i.e., shorter hydroperiods reduce peat accretion, and increase both oxidation and subsidence of organic soils by exposing peat to aerobic conditions (Craft, 1993). Tree islands in Everglades National Park are receiving insufficient amount of water and decreasing in numbers (Sklar pers. Comm.). In most of the Water Conservation Areas 
(WCAs) tree islands are receiving excessive amounts of water. Small tree islands $(<3.2$ ha) have decreased by $98 \%$ in the Water Conservation Area 2A (WCA-2A), tree island density declined from 16 to three islands per 100 ha, and the distance between tree islands increased from $253 \mathrm{~m}$ in 1953 to $874 \mathrm{~m}$ in 1995 (Wetzel et al. 2005). Rutchey et al. (2008) found that in WCA-2A only three tree islands (51 ha) remained compared to the approximately 40 to 50 islands ( $1500 \mathrm{ha}$ ) that previously existed. Tree islands require an adequate hydroperiod that enables the establishment of plant communities, and soil development processes to take place.

The understanding of how different hydroperiods, or the length of time a soil is flooded per year, affect soil building processes on tree islands is important to establish parameters that could be applied by managers to improve the condition of tree islands, reduce their decline in numbers, and increase the understanding of tree island dynamics to be used in restoration projects in the Everglades. The main objective of the present research was to identify processes that are important for tree island structure by determining the influence of hydroperiod on soil building processes under semicontrolled hydrologic conditions. The specific objectives were to determine rates of litter production, rates of litter decomposition, rates of soil accretion, rates of changes in soil elevation, and soil physicochemical characteristics under different hydroperiods in created tree islands, and to determine the characteristics of newly accreted soils. An increase in hydroperiod is expected to increase the amount of organic matter in soils, reduce litter production, and litter decomposition. Shorter hydroperiods are expected to 
increase soil accretion, and create a positive change in soil elevation. Newly accreted soils are expected to be higher in TP concentrations compared to old soils.

\section{STUDY AREA}

This study was conducted at the Loxahatchee Impoundment Landscape Assessment (LILA). The LILA site is located in Boynton Beach, Florida, at the eastern border of the Arthur R. Marshall Loxahatchee National Wildlife Refuge (ARMLNWR). Research in LILA is oriented to test models on hydrology, soils, and vegetation that will reduce uncertainty and help establish targets in restoration efforts for the Everglades.

The purpose of LILA is to model the main landscape features of the everglades (tree islands, ridges, and sloughs) under semi-controlled hydrologic conditions. The LILA site consists of four eight-hectare macrocosms, each composed of two tree islands, a ridge and a slough (Figs. 3 and 4). For this study, tree islands will be labeled as M (macrocosm) 1-4 (macrocosm number) with 1 as the northern-most macrocosm, and 4 the southern-most macrocosm, and W or E (W corresponding to the tree island in the west half of the macrocosm, and $\mathrm{E}$ to the east tree island).

Each 8-ha macrocosm has two tree islands, two ridges, and both a deep and a shallow slough. These landforms were created by mounding (tree islands and ridges) or excavating (sloughs) earth to create the different topographies (Serna et al., 2013). The 
construction of LILA tree islands began in 2002 and was completed in 2003. The M1E, $\mathrm{M} 2 \mathrm{~W}, \mathrm{M} 3 \mathrm{~W}$, and M4E islands were built around a limestone core, obtained from locally mined limestone, and were capped with ca. $0.3 \mathrm{~m}$ of peat (Stofella et al. 2010). The limestone tree islands resemble the tree islands of the southern Everglades whereas M1W, M2E, M3E, and M4W were constructed using the same peat soil found in LILA to resemble the peat tree islands that predominate in the northern Everglades. The slopes of the central plateau of the tree islands were graded 16:1 along the north-south axis and 12:1 along the east-west axis (Stofella et al. 2010).

Water levels in LILA were manipulated via an operational hydrograph developed based on historic water levels recorded at a well-established northern Everglades water level recorder. Stage and water level in LILA lag behind rainfall, with the deepest water levels occurring from September to January and the lowest levels occurring from April to June (Serna et al., 2013). (Fig. 5).

Tree islands were initially planted in 2004 , however the survival rate was less than 10\% (Van der Valk et al., 2008). Successful planting using herbicides and prescribed fire to prepare the tree islands was achieved in the years 2006 and 2007, M1 and M4 were planted in 2006, while M2 and M3 were planted in 2007. Eight species common to the Everglades tree islands were planted with a total of 89 individuals of each species per island. Four planting densities were implemented in each tree island (Fig. 6) with trees arranged along rectangular lattices at spacing of $1.00,1.66,2.33$, and $3.00 \mathrm{~m}$, each quadrant in the tree island was randomly assigned to one of the four planting densities 
allowing for buffer zones of $2 \mathrm{~m}$ (E-W direction) and $3 \mathrm{~m}$ (N-S direction) (Stofella et al. 2010).

\section{METHODS}

Soil building processes at different hydroperiods were determined by measuring rates of litter production, litter decomposition, soil accretion, changes in soil elevation, and physicochemical soil characteristics at two elevations within the tree islands (Head High, HH and Head Low, HL) (Figs. 4 and 7). The HH elevations were located at the center of the tree islands, at HH soils were never flooded, the HL elevations were located down slope of the head of the tree islands, and were flooded between 179 and 271 days $\mathrm{y}^{-}$ ${ }^{1}$ with an average of 232 days $\mathrm{y}^{-1}$ (Fig. 8).

To determine if litter production was higher in locations with shorter hydroperiods, rates of litter production steel wire fine-mesh $\left(0.50 \times 0.50 \mathrm{~m}^{2}\right)$ litter traps were installed on the four western tree islands (six traps per island; $3 \mathrm{HH}$ and $3 \mathrm{HL}$ ) at the heads, at high and low elevations in July 2010. Litter was collected from the traps every two months starting in September 2010 for 12 events until July 2012. Material from the litter traps was transported to the Freshwater Biogeochemistry Laboratory at Florida International University where they were dried to constant weight at $60{ }^{\circ} \mathrm{C}$ for $48 \mathrm{~h}$. and weighed. Litter fall per unit area was determined by dividing the dry weight of litter collected into the trap. Annual rates of litter production were estimated by adding the 
litter collected in each trap across all sampling dates and dividing the value into the number of years recorded.

To determine if rates of litter decomposition were higher in shorter hydroperiods $0.2 \times 0.2 \mathrm{~m}^{2}$ litter bags were constructed with $1.6 \mathrm{~mm}$ fiberglass window screening. Litter used in the experiment was previously collected from the litter layer of the highest density tree planting of the $\mathrm{M} 1 \mathrm{~W}$ tree island. Litter was dried at $60{ }^{\circ} \mathrm{C}$ for $24 \mathrm{~h}$ and used to fill the tared litter bags. Litter-containing bags were then re-dried and reweighted to get an initial litter weight. Ten bags were attached to each litter trap in August 2010 and collected one month later $(30,59,92,120 \mathrm{~d})$ for four events, at two months (180 and 243 d) intervals for two events, and at 4 months $(367,488,606,732$ d) intervals for four events until August 2012. Upon retrieval, bags were gently rinsed of silt and debris with deionized water (Newman et al., 2001), and dried at $60{ }^{\circ} \mathrm{C}$ for a minimum of $24 \mathrm{~h}$ (Wieder et al., 2009) or until constant weight, and then reweighed to determine mass loss and daily decomposition rates (k values). Decomposition rates were determined using the negative exponential decay model of Olson (1963), as given by $\mathrm{Mt}=\mathrm{M}_{0} \mathrm{e}^{-\mathrm{kt}}$, where $\mathrm{M}_{0}$ is the initial mass $\left(\mathrm{M}_{0}, \mathrm{~g}\right)$ and $\mathrm{Mt}(\mathrm{g})$ is the mass remaining at time $\mathrm{t}(\mathrm{d})$.

To determine if shorter hydroperiods produce higher soil accretion three feldspar markers were placed as replicates in proximity to one another $(n=3)$ at the $\mathrm{HH}$, and HL elevations in the high density planting of the eight tree islands, and the tail high (TH), and the tail low (TL). The tail of the tree islands is located downstream with the TH halfway from the base of the tail, and was flooded for an average of $248 \mathrm{~d} \mathrm{y}^{-1}$. The TL was located 
down slope on the deep slough, and was permanently flooded. The TH, and TL locations were not located under the planted vegetation (Fig. 7). Feldspar markers were made using F4 ceramic feldspar (Unimin Corporation). Feldspar was mixed with water to form a consistent paste; the paste was frozen and the resulting discs were then transported to the field where they were deployed. Marker horizons were $44 \mathrm{~cm}$ diameter and between 3 and $5 \mathrm{~cm}$ thick. Accretion measurements were taken by extracting a core at the feldspar locations and measuring the amount of soil that had accreted above the bright white feldspar layer (Fig. 8). Annual measurements were made in 2010, 2011, and 2012 between April and June on each of the eight tree islands.

To test if shorter hydroperiods produce a positive change in soil elevation SET platforms were established on spring 2009 on all eight tree islands. In each island, two SETs are located downstream of the tree islands with one at the TL and the other at the TH locations. Two other SETs were located at the head of the tree islands, one at the HH location, and the other at the HL location on the highest density planting in the vicinity of the feldspar markers, and the litter traps (Fig. 7). The initial SET measurement was made in May 2009 and measurements were repeated during periods of relatively low water stage in LILA, April - May 2010, April 2011, and April - May 2012, at the same time than feldspar maker horizon measurements. The SET arm was fixed at four positions, in each platform. At each position, nine pins were measured for a total of 36 measurements per site (Fig. 9). Measurements were taken from the top of each pin to the arm of the SET, a reduction in a measurement from a previous reading means a positive change in elevation. The SET arm was fixed at the same position each subsequent year to assure 
reoccupation of exactly the same pin position each time. Shallow subsidence was estimated by subtracting change in elevation from soil accretion for the $\mathrm{HH}$ and $\mathrm{HL}$ elevations on the eight tree islands (Fig. 10).

Soil physicochemical characteristics were analyzed by taking $10 \mathrm{~cm}$ soil cores in March 2013. Samples were extracted using cellulose acetate butyrate (CAB) tubes (2.3 $\mathrm{cm}$ diameter) from the four western islands at high and low elevations in the high and low density plantings (four sites per island), samples were taken in triplicates for a total of 12 cores per island, 48 cores total. Cores were separated in two increments: top $(0-3 \mathrm{~cm})$, and bottom $(3-10 \mathrm{~cm})$, the top increment representing newly accreted soil on the basis of previous marker horizons measurements. Soils were analyzed for TP by dry combustion with $\mathrm{MgSO} 4$ in muffle furnace for $2 \mathrm{hr}$ at $550^{\circ} \mathrm{C}$, followed by ash dissolution in $0.24 \mathrm{M}$ $\mathrm{HCl}$ (Solorzano and Sharp, 1980), and a colorimetric analysis using a Technicon Autoanalyzer II System (Pulse Instruments Ltd.), according to the standard method for orthophosphate P (EPA method 365.1). Total nitrogen (TN), and total carbon (TC) were analyzed on oven-dried samples by the high-temperature dry combustion method using a Carlo-Erba NA-1500 CNS Analyzer (Nelson and Sommers, 1996). Organic matter (OM) was determined by loss on ignition (LOI) (Håkanson and Jansson 1983). The pH was determined by using a standard electrode in 1:1 slurries. Field bulk density (FBD) was determined drying soil at $80{ }^{\circ} \mathrm{C}$ and using oven-dry soil mass (g) per unit volume excavated $\left(\mathrm{cm}^{3}\right)$. Phosphorus fractions were calculated to determine in which fraction the $\mathrm{P}$ was predominantly stored on LILA tree islands. Fractions were determined by using a sequencial fractionation procedure modified from Hieltjies and Liklema (1980), and 
Reddy et al., (1998). The fractionation procedure consisted of three solutions: DDI $\mathrm{H}_{2} \mathrm{O}$, $0.5 \mathrm{M} \mathrm{NaCl}$, and $0.5 \mathrm{M} \mathrm{HCl}$. A sample to solution ratio of 1:50 was used. The soil + solution mixture was shaken for $1 \mathrm{~h} ., 30$ mins. and 24 h., for the DDI, $\mathrm{NaCl}$, and $\mathrm{HCl}$ solutions respectively. After equilibration, samples were centrifuged at $2100 \mathrm{rpm}$ for 10 mins., and filtered using nitrocellulose filters $0.45 \mu \mathrm{m}$. The resulting solution was analyzed by colorimetric analysis using a Technicon Autoanalyzer II System (Pulse Instruments Ltd.). Water soluble $\mathrm{P}$, and $\mathrm{P}$ extracted with $\mathrm{NaCl}$ constitute the available $\mathrm{P}$ fraction. The $\mathrm{HCl}$-extracted $\mathrm{P}$ constitutes the inorganic $\mathrm{P}$ fraction, and the difference between TP and the previous fractions constitute the residual $\mathrm{P}$, which includes the organic bound P. C:N, C:P, and N:P molar ratios were calculated by dividing the nutrient concentrations into the molecular weight of each element and calculating the corresponding ratio. To perform comparisons between planting density, substrate, and elevation without discriminating between new and old soil, nutrient concentrations, OM, and FBD were calculated for $0-10 \mathrm{~cm}$ cores by multiplying the respective variables for the corresponding fraction of mass of each increment and adding both increments.

Statistical analysis

Analyses were performed using SPSS 18.0 (SPSS Inc., Chicago, Illinois, USA). Effects were considered significant if $p<0.05$. Shapiro-Wilk's tests, skewness, and kurtosis were used to evaluate data normality (data were considered normally distributed if skewness and kurtosis were between -4 and 4). Data for soil accretion at the tail of tree islands were logarithmically transformed to achieve normality. Comparisons of mean 
values of litter production, soil accretion, changes in soil elevation, and soil physicochemical characteristics (FBD, pH, OM, TP, TN, TC) were performed under the following treatments: elevation (hydroperiod), substrate, year of planting, planting density, and soil increment using ANOVA, and independent samples t-tests. Paired sample t-tests using the combined data of the four macrocosms were performed to compare the soil elevation differences between years 2009 vs. 2010, 2009 vs. 2011, and 2009 vs. 2012 at the head and tail locations. One outlier was removed from the litter trap data from January 2011, three from the litter bag data, one from the soil accretion data, one from the SET data, and one from the lower increment soil data. Kruskal-Wallis tests were used to analyze effects of island core type and elevation on percentage mass remaining in litter bags after $732 \mathrm{~d}$ of decomposition. Annual rates of accretion and change in elevation were estimated using regression analysis. Shallow subsidence was estimated by subtracting mean values of change in elevation rate from mean values of accretion rate. Pearson correlation was used to evaluate relations between TP, TN, TC, $\mathrm{OM}, \mathrm{pH}$, and FBD on soils. Independent sample t-tests were used to compare $\mathrm{P}$ fractions between the two soil increments. Independent samples Mann Whitney tests were used to compare $\mathrm{P}$ fractions as percentage of TP between soil increments. Comparissons of mean values of TP, and available $\mathrm{P}$ between all combinations of soil increments and planting densities were performed using ANOVA. Multiple comparisons for treatments were evaluated with Tukey HSD for TP, and with Dunnet $\mathrm{C}$ for available P. 


\section{RESULTS}

Litter production

The litter fall collected every two months for the two years of the study from the four western tree islands varied seasonally, with the highest average values observed in March 2012 in most macrocosms, especially in M1W where production averaged more than 250 and $120 \mathrm{~g} \mathrm{~m}^{-2}$ in the two elevations $\mathrm{HH}$ and HL respectively (Fig. 11). Litter fall was significantly greater (ANOVA, $\mathrm{p}<0.001 ; \mathrm{n}=287$,) at high elevations $(93.2 \pm 60.2 \mathrm{~g}$ $\left.\mathrm{m}^{-2}\right)$ than at low elevations $\left(49.4 \pm 48.7 \mathrm{~g} \mathrm{~m}^{-2}\right)$. There was significantly higher litter production $(\mathrm{p}<0.001, \mathrm{n}=287)$ in the islands planted in $2006\left(87.1 \pm 65.6 \mathrm{~g} \mathrm{~m}^{-2}\right)$ than in the islands planted in $2007\left(55.6 \pm 46.6 \mathrm{~g} \mathrm{~m}^{-2}\right)$, and there was significantly higher litter production (ANOVA, $\mathrm{p}<0.001, \mathrm{n}=144)$ in the peat $\left(113.9 \pm 64.1 \mathrm{~g} \mathrm{~m}^{-2}\right)$ than in the limestone core tree islands $\left(72.4 \pm 48.2 \mathrm{~g} \mathrm{~m}^{-2}\right)$ (Fig. 12). Annual rates of litter production are higher in higher elevations compared to lower elevations, and in peat substrate compared to limestone substrate (Table 1).

\section{Litter Decomposition}

Decomposition coefficients $(\mathrm{k})$ were similar for all tree islands and elevations (Fig. 13), with nominally higher losses on $\mathrm{M} 4 \mathrm{HH}$ and $\mathrm{M} 2 \mathrm{HL}$ with $83 \%$ and $82 \%$ of the original mass decomposed, respectively; and the lowest in M1 HL with $58 \%$ of the original mass decomposed (Fig. 13). Plant litter decayed steadily, though a few samples increased in biomass to more than the previous collection, presumably because of roots 
growing around the bags, and sediment being trapped within the litter. Comparisons of mass remaining in the litter bags after $732 \mathrm{~d}$ of decomposition showed no significant differences in percentage of mass remaining at different elevations $(n=24, p=0.133$, Kruskal-Wallis tests), and island core type $(\mathrm{p}=0.817)$. Average decomposition rates $(\mathrm{n}=$ 8), expressed in $\%$ loss $\mathrm{mo}^{-1}$ was 2.80 and ranged between 2.43 and $3.44 \%$ loss $\mathrm{mo}^{-1}$.

\section{Feldspar marker horizons}

There was evidence of soil accretion in all islands, in both locations (heads and tails), and at both elevations (high, and low) over time (Figs. 14 and 15), indicating that soil is being developed in all locations of the tree islands. Soil development in the young

tree islands is on average $<1.0 \mathrm{~cm} \mathrm{y}^{-1}$. The head of the tree islands showed significantly greater soil accumulation at high $(2.5 \pm 1.1 \mathrm{~cm})$ than at low elevations $(1.8 \pm 0.8 \mathrm{~cm})$ after three years (2009-2012), (Fig. 14). Soil accumulation in the peat islands (2.2 \pm 0.8 $\mathrm{cm})$ was not significantly different than in limestone islands $(2.6 \pm 1.4 \mathrm{~cm}),(\mathrm{p}=0.422, \mathrm{n}$ $=23)$. The tail of the tree islands showed significantly greater accretion at low $(3.2 \pm 1.6$ $\mathrm{cm})$ than at high elevation $(1.7 \pm 0.5 \mathrm{~cm})($ Fig. 15) after three years.

Surface Elevation Tables and shallow subsidence

The SETs at the head of the tree islands showed that after three years (2009 2012), subsidence occurred at all elevations, but the higher location (HH) experienced a larger decrease in elevation $(-2.72 \pm 2.01 \mathrm{~cm})$ in comparison to the lower elevation (HL, $0.80 \pm 1.90 \mathrm{~cm})$; however the difference was not statistically significant $(\mathrm{p}=0.07, \mathrm{n}=$ 16) (Fig. 15). Peat tree islands experienced the largest loss of elevation $(-3.84 \pm 2.15 \mathrm{~cm})$, 
whereas limestone islands lost less $(-1.59 \pm 1.19 \mathrm{~cm})$. Again, this difference was not statistically significant $(\mathrm{p}=0.115, \mathrm{n}=8)$. In the first and second years most of the SET measurements resulted in little change between sampling events as means fluctuated around zero ( $\mathrm{p}=0.227$ for 2009 vs. 2010 and $\mathrm{p}=0.718$ for 2009 vs. 2011). At the third year (2012) there was a notable loss of elevation compared to the 2009 elevation ( $p=$ 0.005). The loss of elevation was more pronounced at the higher elevation (Fig. 16), but both high and low elevations showed a downward trend reflecting the cumulative change in soil elevation over time. The rate of shallow subsidence at the high elevation at the head of the tree islands was higher compared to the rate of shallow subsidence at the lower elevation at the head of the tree islands (Table 2).

After three years of monitoring (2009-2012) there was variability around zero at the tail of the tree islands at both locations (Fig. 17), the mid-slope TH which exhibited a loss of $-0.61 \pm 0.92 \mathrm{~cm}$ and the base of the tail slope TL which loss $-2.40 \pm 5.42 \mathrm{~cm}$. Changes in elevation between the two elevations were not significantly different $(\mathrm{p}=0.376, \mathrm{n}=8)$. Comparisons of soil elevation of the years 2009 vs. 2010, 2009 vs. 2011, and 2009 vs. 2012 showed no significant differences ( $p=0.675$ for 2009 vs. $2010 ; p=0.603$ for 2009 vs. 2011 , and $p=0.901$ for 2009 vs. 2012) confirming variability around zero.

Soil physicochemical characteristics

The soils from LILA tree islands exhibited a significant positive correlation between organic matter content $\mathrm{OM}$ and concentration of soil nutrients (TP, TN, and TC) (Table 3). The $\mathrm{pH}$ values exhibit a significant negative correlation with $\mathrm{OM}$ and soil 
nutrient concentrations (Table 3). Previous correlation analysis for soil increments separated exhibited the same trends and levels of significance, therefore the two increments $(0-3 \mathrm{~cm}$, and 3-10 $\mathrm{cm})$ were combined.

Top soil represented by the $0-3 \mathrm{~cm}$ increment, on the basis of previous feldspar marker horizon measurements, had significantly higher $\mathrm{TP}, \mathrm{TN}$, and $\mathrm{TC}$ compared to the lower $(3-10 \mathrm{~cm})$ increment (Table 4). Organic matter content was higher in the top soil compared to the lower soil (Table 4). The C:P and N:P molar ratios were significantly higher at deeper soil depths (Table 4), indicating that $\mathrm{P}$ is less limited in the newly accreted soils. Field bulk density was significantly higher at the lower increment compared to the higher increment (Table 4).

The characteristics of the newly accreted $(0-3 \mathrm{~cm})$ soil at the high and low elevations differed. At higher elevations soils had significantly more TP per volume compared to lower elevation soils (Table 5). The C:N molar ratio was significantly higher at higher elevations compared to lower elevations (Table 5). Nutrient concentrations, C:P and $\mathrm{N}: \mathrm{P}$ ratios, $\mathrm{OM}, \mathrm{FBD}$, and $\mathrm{pH}$ were not significantly different between elevations. (Table 5).

The upper $(0-3 \mathrm{~cm})$ of peat soils had lower FBD compared to lower increment soils. Peat soils had higher nutrient concentrations (TP, TN, and TC) compared to limestone soils (Table 6). Organic matter content was significantly higher in peat soils compared to limestone soils as expected. The C:N molar ratio was significantly higher in 
peat soils compared to limestone soils. The N:P ratio was significantly lower in peat soils compared to limestone soils (Table 6). Total phosphorus per volume was significantly higher in peat soils compared to limestone soils (Table 6).

Top soils $(0-3 \mathrm{~cm})$ in the higher planting density have higher $\mathrm{OM}$ content compared to lower planting density soils. High planting density soils had lower FBD compared to low planting density soils (Table 7). High density planting soils have higher $\mathrm{TN}$, and TC concentrations compared to low planting density soils. The C:N molar ratio was significantly higher at the higher planting density soils compared to the lower planting density soils. The TP per unit volume is significantly higher in top soil under the high density planting compared to the low density planting, although TP concentrations were not significantly different between the two planting densities (Table 7). There were significant differences in TP between new and old soil that were more pronounced in the high planting density. Newly accreted soils at the high planting density had the highest TP concentrations indicating the influence of vegetation in soil nutrients (Fig. 18).

Top soils had significantly higher concentrations of available $\mathrm{P}, \mathrm{Ca}-\mathrm{Mg} \mathrm{P}$, and residual P compared to lower soils (Fig. 19). Available P, as percentage of TP, was significantly higher $(7.2 \% \pm 2.5)$ at the top soil compared to the lower soil $(6.2 \% \pm 6.9)$ $(\mathrm{p}<0.001)$. Ca-Mg P and residual $\mathrm{P}$ were not significantly different between the two soil increments. There were significant differences in available $\mathrm{P}$ between new and old soils that were more pronounced at the high planting density. New soils in the high planting density had the highest available P concentrations (Fig. 20). 
To compare the soils without the influence of depth, and determine if $0-10 \mathrm{~cm}$ cores exhibit similar differences between substrates, elevations, and planting densities, as those showed in newly accreted soils $0-10 \mathrm{~cm}$ cores were analyzed. For these data, soils of peat core islands had significantly higher TP, and TC concentrations compared to soils from limestone core islands. Soils from peat core islands had lower FBD compared to soils from limestone islands. Organic matter was significantly higher in soils from peat islands compared to soils from limestone islands. Total phosphorus per volume was significantly higher in soils from peat islands compared to soils from limestone islands. (Table 8)

The $0-10 \mathrm{~cm}$ cores had higher $\mathrm{P}$ concentrations at low elevations compared to high elevations. Phosphorus per volume was higher in low elevations compared to low elevations. Organic matter was higher in lower elevations compared to higher elevations. All parameters were not significantly different between the two planting densities (Table 8). 


\section{DISCUSSION}

Litter production

Litter production was higher in higher elevations and therefore in shorter hydroperiods within tree islands. Rates of trees survival and growth were found to be higher in higher elevations within LILA tree islands with species adapted to flooded conditions less susceptible to be affected by an increase in hydroperiod (Scinto et al., 2013). Natural tree islands with low elevation are dominated by species that can also be found at lower elevations of high natural tree islands (Van der Valk et al., 2008). Species found in tree islands are adapted to different hydroperiod conditions. Since the arrangement of plant species in LILA tree islands was done in a random way (without considering differential tolerance of species to flooded conditions), mortality was higher at lower elevations affecting those species that could not tolerate those hydrologic conditions, differential mortality in turn, was transformed into less litter being produced at lower elevations and also less inputs to the soils. Pande et al., (2002) reported annual rates of litter production from 264 to $497 \mathrm{~g} \mathrm{~m}^{-2} \mathrm{y}^{-1}$ for a tropical dry deciduous forest in Chhindwara, India. Luizao and Shubart (1987) reported rates of litter production between 607 to $742 \mathrm{~g} \mathrm{~m}^{-2} \mathrm{y}^{-1}$ for a tropical forest in Manaus, Brazil. Ross et al. (2003) found rates of litter production between 290 and $740 \mathrm{~g} \mathrm{~m}^{-2} \mathrm{y}^{-1}$ on five typer of upland forest in the Florida Keys. Rates of litter production in LILA tree islands were $559 \mathrm{~g} \mathrm{~m}^{-2} \mathrm{y}^{-1}$ for higher elevations, and $308 \mathrm{~g} \mathrm{~m}^{-2} \mathrm{y}^{-1}$ for lower elevations. Rates of litter production in this recreated tree islands are close to those of tropical forests. 
Litter production was higher in peat tree islands compared to limestone tree islands. Peat substrate in LILA tree islands favors a faster growth compared to limestone substrate (Scinto et al., 2013). Van der Valk et al. (2008) suggested that limestone cores may be a source of nutrients for tree seedlings. Sullivan et al. (2010) found a depression in the water table on LILA tree islands which was more pronounced in the limestone core islands compared to the peat islands, which indicate that trees in limestone islands use more efficiently groundwater resources. These results however do not correspond to our findings in litter production. Peat substrate is a source of nutrients and resources that maximize productivity in terms of litter production.

Zalamea et al. (2012) found that the most important factors controlling relative abundance of litter fall from species in a litter fall experiment using litter traps were the height and crown area for a subtropical wet forest in north eastern Puerto Rico. Litter production in LILA tree islands is correlated to tree crown area (Scinto et al., 2013) meaning that trees with big crown areas are the main contributors to litter inputs into the soil. Big trees with big crown areas can be found mainly in peat substrate (because peat supports rapid growth), and in older plantings in which trees have had more time to grow. The fact that year of planting was controlling litter production with older plantings producing more litter than the most recent plantings was expected and indicates that trees in these reconstructed tree islands are actively growing after five and six years of planting and they have not reached a plateau in terms of litter production. 
The seasonality that can be suggested from the pattern of litter production with peaks around March and July corresponds to relatively low water levels according to the LILA hydrograph in what would be the beginning of the rainy season and still in relatively low temperatures (for the case of March). Patterns in litter production are responsive to environmental conditions such as climate, temperature, and rainfall (Luizao and Shubart, 1987; Pande et al., 2002; and Juman, 2005). The peaks of litter production in LILA may also be related to leaf shedding cycles of deciduous and semi-deciduous species planted in the tree islands.

Of all tree islands $\mathrm{M} 1 \mathrm{~W}$ had the highest rates of litter production. M1W and M4W were planted in the same year (2006), and have the same peat substrate, The difference in litter production between these two tree islands could be attributed to the fact that M4W had a high initial mortality rate due to a locust attack (Susana Stoffella, pers. comm.). Higher litter production produces higher nutrient inputs into the soil. Nutrient concentrations in LILA tree island soils were found to be positively correlated to OM. A substantial amount of organic matter returns to the soil via litter fall (Pande et al., 2002). Litter production can be one of the main drivers in producing distinctive nutrient concentrations in tree islands by serving as a source of OM to the soil.

\section{Litter decomposition}

Litter decomposition rates did not follow the expected pattern (lower at lower elevation of tree islands, compared to higher elevations), produced by reduced conditions 
on flooded soils. Instead, decomposition rates did not differ significantly from each other. Differences in hydroperiod, such as the ones that experience LILA tree islands (an average of 232 days $\mathrm{y}^{-1}$ for lower elevations compared to soils which are never flooded at the high elevation) are not enough to produce differences in litter decomposition rates, another explanation for the similar rates of decomposition may be that the method employed is difficult to apply in highly organic soils. To get rid of sediments and roots in the decomposition bags was difficult, and if differences in decomposition rates are not big, they may appear similar as a result of the methodological problem. Previous studies suggest that decomposition is partially controlled by the initial litter chemistry (Currie and Aber, 1997; Murphy et al., 1998; Serna et al., 2013). Wieder et al. (2009) found that decomposition rates varied significantly between species in a tropical rain forest in Costa Rica. These previous findings indicate that initial characteristics of the litter, which vary among different species, are one of the main factors controlling rates of decomposition.

The decomposition rates found in my study (from 2.43 to $3.44 \%$ loss $\mathrm{mo}^{-1}$ ) were similar to rates of decomposition calculated by Rubio and Childers (2006) for macrophyte species; 2.40 and $2.48 \%$ loss $\mathrm{mo}^{-1}$ for Cladium jamaicense and Juncus roemerianus in Taylor Slough, Everglades. However, rates of decomposition are slow compared to tropical forests, and can be classified as slow $(\mathrm{k}<0.005)$, according to the classification of Petersen and Cummins (1974). Slow rates of decomposition in LILA tree islands may be a product of high quantity of recalcitrant materials such as lignin present in the litter. The seemingly constant decomposition rate, and low values of litter remained 
after the two years of the study show that decomposition takes place at an active and constant rate in LILA tree islands.

Soil accretion

Soil development at LILA had an average of $0.69 \mathrm{~cm} \mathrm{yr}^{-1}$ at the head of tree islands. Accretion in LILA tree islands exceed other areas of the Everglades. Craft and Richardson, (1998) found rates of accretion between $\left(0.08\right.$ and $\left.0.12 \mathrm{~cm} \mathrm{yr}^{-1}\right)$ for the northern NWR. Craft and Richardson (1993) found rates of accretion between 0.2 and $0.56 \mathrm{~cm} \mathrm{yr}^{-1}$ in the proximity of the Hillsboro Canal in WCA2, and in other wetlands, Cahoon and Turner, (1989) found average rates of accretion between 0.7 and $1.3 \mathrm{~cm} \mathrm{yr}^{-1}$ in canals and waterways in Louisiana. Tree islands not only depend on the input of sediments to develop new soil, litter in tree islands allows more rapid soil formation compared to the surrounding marsh. The rate of accretion found in LILA tree islands is comparable to rates of accretion found by Cahoon and Lynch, (1997) within a mangrove forest in Rookery bay, Florida. They found mean rates of accretion from 0.44 to $0.72 \mathrm{~cm}$ $\mathrm{yr}^{-1}$. Mangrove forests are similar to tree islands because they are slightly elevated compare to the surroundings (at least some of them), are dominated by trees, and don't have allocthonous sediment inputs. Litter input in both systems is important for soil development.

Rates of accretion vary depending on nutrient loadings (Craft and Richardson, 1998) (Cahoon and Turner, 1989) with high nutrient sediment/waters producing higher rates of accretion, and pulsing events (Whelan et al., 2009) (Day Jr et al., 1999) with 
pulsing events bringing more sediments and consequently producing higher rates of accretion. Litter production in tree islands generates a constant input of organic matter and nutrients into tree islands soils. Higher nutrient inputs in turn favor the establishment and growth of trees establishing a positive feedback mechanism that allows tree islands to survive. Nyman et al. (1993) found a feedback loop in which vertical accretion depended on organic matter accumulation, and this in turn depended on plant production in a Terrebone Basin in Louisiana, USA.

Rates of soil accretion were higher at higher elevations at the head of tree islands with a mean value of $0.78 \mathrm{~cm} \mathrm{yr}^{-1}$ compared to the lower elevations $0.60 \mathrm{~cm} \mathrm{yr}^{-1}$. The same trend was also found in litter production (higher litter production at higher elevations). Differences in rates of soil accretion may suggest a positive relation between litter production and soil accretion indicating that the more litter is produced the more soil is accreted, and suggesting that litter production is crucial for soil development in tree islands.

At the tail of the tree islands there was more accretion at the lower elevation compared to the higher elevation. The tail of these tree islands act like a marsh environment. There are no trees present there so all the inputs come from sediments and from the emergent vegetation that dominates this part of the island. The lower elevation at the tails is constantly flooded allowing favorable conditions for emergent vegetation to establish and proliferate there, when this vegetation is established there are more sediments being trapped and accretion takes place. Considerable floc (unconsolidated 
soil), which is mostly water is present at the TL, the floc can be considered as part of the soil formation process at the tail of tree islands, and show the initial sediments being trapped, which later will be incorporated into the soil. Soil accretion at the tail of LILA tree islands could be the beginning of the process of tail elongation that can be seen in natural tree islands, however this process can take a long time. Willard et al. (2002) reported that maturation of the Gumbo Limbo and Nuthouse tree islands located in the Water Conservation Area (WCA) 3B took between 1000 and 2000 years.

\section{Soil elevation changes}

The LILA tree islands are losing elevation. The loss of elevation does not occur in a uniform way. The center of the tree islands lost more elevation than other parts of the tree islands. The head high elevation of the tree islands which was the part of the tree islands that in general lost more elevation is also the part of the tree islands where more litter is being produced, more biomass, and more accretion occurred too. The presence of considerable biomass is a big factor affecting soil elevation. Cahoon et al., (2003) found that tree mortality induced loss of soil elevation by producing peat collapse after root decomposition in a mangrove forest in Honduras. The higher elevation in LILA tree islands is more susceptible to change of elevation produced by peat collapse because it sustains more trees. Cahoon et al., (2003) found that stronger substrates, with higher density, respond less quickly to tree mortality, therefore peat soils with low bulk density were expected to respond fast to tree mortality, thereby losing elevation. There were not significant differences between limestone and peat substrates in terms of change in soil elevation, however, peat substrates had the largest losses of elevation and this may be 
explained because peat substrate has a lower FBD, being more susceptible to loss of elevation. Also the higher tree mortality in peat substrates at LILA produced more peat decomposition and peat collapse. Scinto et al., (2013) found that limestone substrates exhibit better survival rates compared to peat substrates. The difference in survival rates may be a consequence of the higher density and strength of limestone soils which reduces the negative change in soil elevation.

Changes in hydroperiod produced changes in soil elevation. Water going into the pore spaces in the soil may expand soils. Whelan et al. (2009) found changes in soil elevation greater than rates of accretion in a mangrove forest in Everglades National Park after Hurricane Wilma. The authors hypothesized that water going into the soil layer could expand it. Similar changes in elevation can be produced in tree islands in response to changes in hydroperiod. Longer hydroperiods such as the ones experienced by lower elevation of tree islands can increase swelling of the substrate and reduce negative changes in soil elevation.

Changes in elevation at the tails of tree islands only fluctuated around zero. Vegetation structure is different at the tails of LILA tree islands compared to the head locations. At the tail there is no influence of planted trees, and therefore the predominant input for soils are sediments that are moved by the flowing water. The sediments at the tails of tree islands are not well consolidated and changes in elevation are difficult to determine, Producing variability of the SETs measurements at the tail of the tree islands. Boumass and Day Jr. (1993) concluded that the SET is more accurate if pins are lowered 
manually and if the sediment surface is determined visually. Cahoon et al., (2002) reported higher error given by the SET when measuring flooded surfaces. At the tail low elevation soils are always flooded and soil surface cannot be determined visually. These reasons may also explain the high variability of the change in elevation at the tail low location of the tree islands.

Shallow subsidence

Rates of shallow subsidence were considerably higher at higher elevations at the head of LILA tree islands compared to lower elevations. At higher elevations there was also more litter production and more accretion. Cahoon and Lynch (1997) found a similar pattern in a mangrove forest at Rookery Bay, Florida. In their study the fringe forest had the highest rates of accretion, and the highest shallow subsidence. In LILA tree islands there is no erosion because of the semi-controlled hydrologic conditions; therefore subsurface processes dominate changes in elevation. The new material accreted on top of the soil profile has higher OM and lower FBD compared to older soils and has to go through a process of consolidation in which it loses density, and produces negative changes in soil elevation. Although rates of accretion were high, accretion was not enough to produce a positive change in elevation. Low bulk density of peat soils made them vulnerable to shallow subsidence. A prolonged hydroperiod that causes tree mortality, root decomposition and peat collapse could be the most direct way in which shallow subsidence could be affected by water level. Shallow subsidence appear to be higher in places where there is more litter production, and more tree growth (estimated 
based on crown area), which suggest that large amounts of biomass could also increase subsidence in unconsolidated soils.

Soil physicochemical characteristics

Total phosphorus concentrations in LILA tree islands are very low compared to other tree island studies. Irick et al. (2013) found mean TP values of $4720 \mu \mathrm{g} \mathrm{g}^{-1}$ in tree islands of the southern Florida Everglades. Orem et al. (2002) found mean TP concentrations of 3000 and $1500 \mu \mathrm{g} \mathrm{g}^{-1}$ at the head of the Gumbo Limbo and Nuthouse tree islands in the Water Conservation Area (WCA) 3B. Total phosphorus concentrations at LILA tree islands are closer to concentrations present in other parts of the Everglades. Noe et al. (2001) summarized several Everglades studies and found mean TP values of 533.2 for sawgrass environments, and $467.1 \mu^{g^{-1}}$ for slough environments. Reddy et al. (1998) reported mean values of TP concentrations for WCA 1 of $544 \mu \mathrm{g} \mathrm{mg-1,} \mathrm{and}$ Rivero et al. (2007) found mean TP concentrations of $550.7 \mu \mathrm{g} \mathrm{g}^{-1}$ for WCA 2A. The TP concentrations are not homogeneous in these areas of the Everglades. Nutrient loadings affect nutrient concentrations in the soils with more impacted areas having higher TP concentrations. The current concentration of TP in LILA tree islands resembles the original characteristics of the soils with which tree islands were built (on average $400 \mu \mathrm{g}$ TP $\left.\mathrm{g}^{-1}\right)$. TP concentrations have not increased to levels comparable to natural tree islands because processes that concentrate phosphorus take a longer time than the time since LILA tree islands were constructed. The TN and TC concentrations are closer to the values reported by other studies. Irick et al. (2013) found mean TN values of $12.7 \mathrm{mg} \mathrm{g}^{-1}$, and mean $\mathrm{TC}$ values of $200 \mathrm{mg} \mathrm{g}^{-1}$. 
Top soil represented by the $0-3 \mathrm{~cm}$ increment had significantly higher OM, and nutrient concentrations (TP, TN, and TC) compared to the deeper increment. The pattern of higher nutrient concentrations in the top soil was also found in wetlands in WCA 3, using $5 \mathrm{~cm}$ increments (Wang et al., 2011), and in TP concentrations in WCA 2A (Rivero et al., 2007). The opposite pattern (an increase in nutrient concentrations with depth) was found for TN, and TC at Everglades National Park, and for TN and TC in WCA 2A (Rivero et al., 2007). Higher TP concentrations in newly accreted soils were expected in LILA tree islands compared to older soils. Soils produced under tree islands conditions such as an established plant community in an elevated surface compared to the marsh were expected to set in motions mechanisms such as subsurface water flow to islands, and guano accumulation from birds that have been considered as the way in which tree islands concentrate P (Wetzel et al., 2005). The TN, TC, and OM were also higher in the newly accreted soil suggesting that the higher nutrient concentrations have an organic origin, as indicated also by the positive correlation between OM, TP, TN, and TC. The C:P and N:P molar ratios were significantly lower in the newly accreted soil as a consequence of the higher $\mathrm{P}$ concentrations present in the top soil compared to the lower soils.

All P fractions were significantly higher in the top soil compared to lower soil. Most of the $\mathrm{P}$ was stored in the residual pool, which also includes organic $\mathrm{P}$. These results support the strong correlation between OM and TP that was previously mentioned. Tree islands in the southern Florida Everglades behave in a different way with $>80 \%$ of the $\mathrm{P}$ bound in an inorganic form, and approximately $10 \%$ bound in an organic form 
(Irick et al. 2013). The pattern found in LILA tree islands resembles more the one found by Reddy et al. (1998) in WCA 1 in which organic P was between 53 and $84 \%$ of TP, and inorganic P represented between 9-47 \% of TP with lower percentages in less polluted areas. The difference between the pattern found in the tree islands in the southern Everglades and LILA tree islands may be explained because the mechanisms by which P bounds to $\mathrm{Ca}$ and $\mathrm{Mg}$ are not predominant in LILA tree islands and $\mathrm{P}$ is instead bound to organic compounds. The fact that available $\mathrm{P}$ is significantly higher as a fraction of TP in the top soil compared to the older soil links $\mathrm{P}$ concentrations with productivity and indicates that newly accreted soil is a better substrate for trees to grow because $\mathrm{P}$ is more available.

The effect of elevation in newly accreted soils could only be detected in TP per volume with significantly higher values at higher elevations compared to lower elevations, and in C:N ratios which were higher in higher elevations. Total phosphorus per volume was higher at higher elevations presumably because at higher elevations there is more litter production as well as more accretion, meaning that the nutrient input is higher, and produces more $\mathrm{P}$ per volume. The $\mathrm{C}: \mathrm{N}$ molar ratios indicate that $\mathrm{N}$ is more limiting at higher elevations compared to lower elevations in top soils, which means that at higher elevations where vegetation is dominated by trees $\mathrm{N}$ begins to be a limiting nutrient.

Newly accreted soils from peat substrates had higher nutrient concentrations, and higher OM. These findings support the idea that peat substrates promote rapid tree 
growth. Rapid tree growth increases litter production, accretion, and OM inputs into the soil. Higher nutrient concentrations correspond to higher OM inputs. The significantly higher $\mathrm{C}: \mathrm{N}$ and lower $\mathrm{N}: \mathrm{P}$ ratios in peat soils support the idea that in places where there is more tree productivity $\mathrm{N}$ is the limiting nutrient.

Newly accreted soils at the higher planting density had higher OM, TN, TC, and TP per volume compared to soils from the low planting density. These findings support the idea that more tree productivity like the one that can be found at the high planting density produces more $\mathrm{OM}$ and increases nutrient concentrations, in this case TN, and TC. The fact that TP per volume is higher in the high planting density is a consequence of the higher litter inputs received by the soil.

New soils at the high planting density had the highest values of TP, and available P. This shows that vegetation influences soil nutrient concentrations. The high litter production at the high planting density produces higher $\mathrm{P}$ concentrations compared to soils which receive less litter input such as the soils located at the low planting density. Total $\mathrm{P}$ is positively correlated to $\mathrm{OM}, \mathrm{TN}$, and $\mathrm{TC}$ therefore $\mathrm{OM}, \mathrm{TN}$, and $\mathrm{TC}$ are expected to follow the same trend. Higher litter input produces in turn higher nutrient concentrations building soil with higher nutrients which in turn can support a better plant growth.

Results from the soils analyzed as $0-10 \mathrm{~cm}$ cores indicate peat substrates have higher OM, and nutrients compared to limestone soils because the influence of limestone 
substrate at the lower soil does not contribute in the same way as peat does to OM and its associated nutrients. Low elevations show higher P concentrations and OM compared to high elevations. Serna et al., (2013) found low nutrient concentrations in LILA sloughs which they attributed to the grading process involved in LILA construction; however, low elevations within LILA tree islands were not affected by grading because no soil was removed from tree islands in the construction process. Higher TP, and OM concentrations at lower elevations occurred possibly because at this elevation there are longer hydroperiods, a reduction in microbial activity, and there is more peat accumulation. Longer hydroperiod sites are also more exposed to nutrients present in the water, which acts as a nutrient source (Newman et al., 1997).

\section{CONCLUSIONS}

After six and seven years of planting in recently constructed tree islands in LILA, soil building processes are taking place at a very active rate. Hydroperiod affects tree productivity. Trees exposed to shorter hydroperiods produce more litter. Soil accretion is related to tree productivity, and is therefore higher in shorter hydroperiod locations within tree islands. Subsidence is higher in places where there is more accretion, and litter production. Soil nutrients are related to OM. Peat substrates promote faster tree growth, and soil accretion, but are also more susceptible to subsidence. Soil nutrients in LILA tree islands differ from natural tree islands of the Everglades, particularly in TP 
concentrations, which have not reached yet the very high concentrations exhibited by tree islands. Though biogeochemical characteristics of natural tree islands are not present yet in these young tree islands, presumably because time has not been enough to establish the mechanisms that allow such conditions, soil nutrients are increasing because of the addition of OM to the soil. Recreating tree islands provides a means of establishing plant communities, but long-term survival of these forests depend on continued soil development. In order to evaluate their long term viability, further research and monitoring is required to determine the trend the young tree islands described here will follow, particularly in view of the shallow subsidence observed over the three years of my study. 


\section{LITERATURE CITED}

Aich, S., T.W. Dreschel, E.A. Cline, and F.H. Sklar. 2011. The development of a geographic information system (GIS) to document research in an Everglades physical model. J. Environ. Sci. Eng. 5:289-302

Bazante, J., G. Jacobi, H.M. Solo-Gabriele, D. Reed, S. Mitchell-Bruker, D.L. Childers, L. Leonard, and M. Ross. 2006. Hydrologic Measurements and Implications for Tree Island Formation Within Everglades National Park. Journal of Hydrology 329: 606-619.

Boumans, R. M. J. and Day Jr, J. W. 1993. High Precision Measurements of Sediment Elevation in Shallow Coastal Areas Using a Sedimentation-Erosion Table. Estuaries. Vol. 16, No. 2: 375-380.

Brown, M. T., M. J. Cohen, E. Bardi, and W. W. Ingwersen. 2006. Species Diversity in the Florida Everglades, USA: A Systems Approach to Calculating Biodiversity. Aquatic Sciences 68: 254-277.

Cahoon, D. R. and Turner, R. E. 1989. Accretion and Canal Impacts in a Rapidly Subsiding Wetland II. Feldspar Marker Horizon Technique. Estuaries. Vol. 12, No.4: 260-268.

Cahoon, D. R., D. J. Reed, J.W. Day Jr. 1995. Estimating Shallow Subsidence in Microtidal Salt Marshes of the Southeastern United States: Kaye and Barghoorn Revisited Marine Geology. 128: 1-9.

Cahoon, D. R. and Lynch, J. C. 1997. Vertical Accretion and Shallow Subsidence in a Mangrove Forest of Southwestern Florida, U.S.A. Mangroves and Salt Marshes 1: 173186.

Cahoon, D. R, P.E. Marin, B.K. Black, and J.C. Lynch. 2000. A Method for Measuring Vertical Accretion, Elevation, and Compaction of Soft, Shallow-Water Sediments. Journal of Sedimentary Research . Vol. 70, No. 5: 1250-1253.

Cahoon D. R., J.C. Lynch, B.C. Perez, B. Segura, R. D. Holland, C. Stelly, G. Stephenson, and P. Hensel. 2002. High-Precision Measurements of Wetland Sediment Elevation: II. The Rod Surface Elevation Table. Journal of Sedimentary Research. 72: 734-739. 
Cahoon, D.R., P. Hensel, J. Rybczyk, K.L. McKee, C. E. Proffitt, and B. C. Perez. 2003. Mass tree mortality leads to mangrove peat collapse at bay islands, Honduras after hurricane Mitch. Journal of Ecology. 91: 1093-1105.

Cahoon, D. R. A review of Major Storm Impacts on Coastal Wetland Elevations. Estuaries and Coasts (2006) Vol. 29, No. 6A: 889-898.

Craft, C. B. and Richardson, C. J. Peat. 1993. Accretion and N, P, and Organic Accumulation in Nutrient-Enriched and Unenriched Everglades Peatlands. Ecological Applications 3(3): 446-458.

Currie, W.S., and J.D. Aber. 1997. Modeling leaching as a decomposition process in humid montane forests. Ecology 78:1844-1860.

Day Jr., J. W., D. Pont, P.F. Hensel, C, Ibanez. 1995. Impacts of Sea Level Rise on Deltas in the Gulf of Mexico and the Mediterranean: The Importance of Pulsing Events to Sustainability. Estuaries. Vol. 18, No. 4: 636-647.

DeBusk, W. F., and K.R. Reddy. 1998. Turnover of detrital organic carbon in a nutrientimpacted Everglades marsh. Soil Sci. Soc. Am. 62: 1460-1468.

Finotti, R., S. Rodrigues Freitas, R. Cerqueira, and M. Vinicius Vieira. 2003. A method to determine the minimum number of litter traps in litterfall studies. Biotropica. 35 (3): 419-421.

Givnish, T. J., J. C. Volin, V. D. Owen, V.C. Volin, J. D. Muss, and P.H. Glaser. 2008. Vegetation Differentiation in the Patterned Landscape of Central Everglades: Importance of Local and Landscape Drivers. Global Ecology and Biogeography. 17: 384-402.

Irick, D. L., C.L. Yuncong, P.W. Inglett, W.G. Harris, B. Gu, M.S. Ross, A.L. Wright, and K.W. Migliaccio. 2013. Characteristics of soil phosphorus in tree island hardwood hammocks of the southern Florida Everglades. Soil Sci. Soc. Am. Vol. 77 No. 3: 10481056.

Juman, R.A. 2005. Biomass, litterfall and decomposition rates for the fringed Rhizophora mangle forest lining the Bon Accord Lagoon, Tobago. Rev. biol. trop vol. 53. Suppl. 1.

Larsen, L., N. Aumen, C. Bernhardt, V. Engel, T. Givnish, S. Hagerthey, J. Harvey, L. Leonard, P. McCormick, C. McVoy, G. Noe, M. Nungesser, K. Rutchey, F. Sklar, T. 
Troxler, J. Volin, and D. Willard. 2011. Recent and historic drivers of landscape change in the Everglades ridge, slough, and tree island mosaic. Crit Rev Environ Sci Technol. 41 (S1):344-381

Luizao, F.J., and H.O.R. Shubart. 1987. Litter production and decomposition in a terrafirme forest of Central Amazonia. Experientia. 43: 259-265.

Murphy, K.L., J.M. Klopatek, and C.C. Klopatek. 1998. The effects of litter quality and climate on decomposition along an elevational gradient. Ecol. Appl. 8:1061-1071.

Nelson, D.W., and Sommers, L.E., 1996, Total carbon, organic carbon, and organic matter. P. 961-1010. In D.L. Sparks (ed.) Methods of Soil Analysis No.5 Part 3, Chemical Methods. Soil Science Society of America, Inc. Madison, WI. USA.

Newman, S., K.R. Reddy, W.F. DeBusk, Y. Wang, G. Shih, and M.M. Fisher. 1997. Spatial distribution of soil nutrients in a northern Everglades marsh: Water Conservation Area 1. Soil Sci. Soc. Am. J. 61:1275-1283.

Newman, S., H. Kumpf, J.A. Laing, and W.C. Kennedy. 2001. Decomposition responses to phosphorus enrichment in an Everglades (USA) slough. Biogeochemistry 54:229-250.

Nyman, J.A., R.D. DeLaune, H.H. Roberts, and W.H. Patrick Jr. 1993. Relationship between vegetation and soil formation in a rapidly submerging coastal marsh. Mar. Ecol. Prog. Ser. Vol. 96: 269-279.

Noe, G.B., D.L. Childers, and R.D. Jones. 2001. Phosphorus Biogeochemistry and the Impact of Phosphorus Enrichment: Why Is the Everglades so Unique? Ecosystems 4: 603-624.

Olson, J.S. 1963. Energy storage and the balance of producers and decomposers in ecological sytems. Ecology 44(2):322-331.

Orem, W. H., D. A. Willard, H. E. Lerch, A. L. Bates, A. Boylan, and M. Comm. 2002. Nutrient geochemistry of sediments from two tree islands in Water Conservation Area 3B, the Everglades, Florida. In: F. H. Sklar and A. van der Valk, editors, Tree Islands of the Everglades. Kluwer Academic Publishers, Dordrecht, the Netherlands: 153-186. 
Osborne T.Z., G.L. Bruland, S. Newman, K.R. Reddy, and S. Grunwald. 2011. Spatial distributions and eco-partitioning of soil biogeochemical properties in the Everglades National Park. Environ. Monit. Assess. 183: 395-408.

Pande, P. K., P.B. Meshram, and S.K. Banerjee. 2002. Litter production and nutrient return in tropical dry deciduous teak forest of Satpura plateau in central India. Tropical Ecology 43(2): 337-344.

Perry, W. 2004. Elements of South Florida's Comprehensive Everglades Restoration Plan. Ecotoxicology 13: 185-193.

Petersen, R.C., and K.W. Cummins. 1974. Leaf processing in a woodland stream. Freshwater Biol. 4:343-368

Reddy, K.R., Y. Wang, W.F. DeBusk, M.M. Fisher, and S. Newman. 1998. Forms of soil phosphorus in seleceted hydrologic units of the Florida Everglades. Soil Sci. Soc. Am. J. 62:1134-1147.

Rivero, R.G., S. Grunwald, T.Z. Osborne, K.R. Reddy, and S. Newman. 2007. Characterization of the spatial distribution of soil properties in Water Conservation Area 2A, Everglades, Florida. Soil Science. Vol. 172. No 2: 149-166.

Ross, M. S., C.L. Coultas, and Y.P. Hsieh. 2003. Soil-productivity relationships and organic matter turnover in dry tropical forests in the Florida Keys. Plant and Soil 253: 479-472.

Ross, M. S., S. Mitchell-Brucker, J.P. Sah, S. Stothoff, P.L. Ruiz, D.L. Reed, K. Jayachandran, C. L. Coultas. 2006. Importance of Hydrology and Nutrient Limitation in the Ridge and Slough Landscape of the Southern Everglades. Hydrobiologia 569: 37-59.

Rubio, G., and D.L. Childers. 2006. Controls on herbaceous litter decomposition in the estuarine ecotones of the Florida Everglades. Estuaries and Coasts 29(2):257-268

Rutchey, K., T. Schall, and F. Sklar. 2008. Development of Vegetation Maps for Assessing Everglades Restoration Progress. Wetlands. Vol. 28 No. 3: 806-816. 
Scinto, L.J., R.M. Price, M.S. Ross, and A. Serna. 2013. South Florida Water Management District (SFWMD) Final Report: LILA (Loxahatchee Impoundment Landscape Assessment) Tree Island, Ridge, Slough Studies and Site Management. Contract No. 4600001816. Report Period: July 12, 2009 to September 17, 2012. Submitted by Florida International University to SFWMD.

Serna, A., J.H. Richards, and L.J. Scinto. 2013. Plant decomposition in wetlands: effects of hydrologic variation in a recreated Everglades. J. Environ. Qual. 42:562-572

Solorzano, L., and Sharp, J.H., 1980, Determination of total dissolved phosphorus and particulate phosphorus in natural waters: Limnology Oceanography, v. 25, p. 754-758.

Stofella, S. L., M.S. Ross, J.P. Sah, R.M. Price, P. Sullivan, E.A. Cline, and L.J. Scinto. 2010. Survival and Growth Responses of Eight Everglades Tree Species Along an Experimental Hydrological Gradient on Two Tree Island Types. Applied Vegetation Science. 13: 439-449.

Sullivan, P.L., Price, R.M., Ross, M.S., Scinto, L.J., Stoffella, S.L., Cline, E., Dreschel, T.W., and Sklar, F.H. 2010. Hydrologic processes on tree islands in the Everglades (Florida, USA): tracking the effects of tree establishment and growth. Hydrogeol. J. 19:367-378.

Troxler G., T. G., D.L. Childers, and D.N. Rondeau. 2005. Ecosystem Structure, Nutrient Dynamics, and Hydrologic Relationships in Tree Islands of the Southern Everglades, Florida, USA. Forest Ecology and Management. 214: 11-27.

Troxler G., T. and Childers, D. L. 2006. Relationships Between Hydrology and Soils Describe Vegetation Patterns in Seasonally Flooded Tree Islands of the Southern Everglades, Florida. Plant and Soil. 279: 271-286.

Troxler, T. G. and Childers, D. L. 2009. Litter Decomposition Promotes Differential Feedbacks in an Oligotrophic Southern Everglades Wetland. Plant Ecology 200: 69-82.

Van der Valk, A.G., P. Wetzel, E.A. Cline, and F.H. Sklar. 2008. Restoring tree islands in the Everglades: experimental studies of tree seedling survival and growth. Restoration Ecology 16(2):281-289

Van Dyke, E. 2012. Water Levels, Wetland Elevations, and Marsh Loss. Elkhorn Slough Technical Report Series 2012:2. 
Wang, Q., Y. Li, and Y. Ouyang. 2011. Phosphorus fractionation and distribution in sediments from wetlands and canals of a water conservation area in the Florida Everglades. Water Resources Research, Vol. 47, 5.

Wetzel, P. R., A.G. Van der Valk, S. Newman, D.E. Gawlik, T. Troxler Gann, C.A. Coronado-Molina, D.L. Childers, and F.H. Sklar. 2005. Mantaining Tree Islands in The Florida Everglades: Nutrient Redistribution is the Key. Frontiers in Ecology and the Environment; 3(7): 370-376.

Whelan, K.R.T., T.J. Smith III, G.H. Anderson, and M.L. Ouellette. 2009. Hurricane Wilma's Impact on Overall Soil Elevation and Zones Within the Soil Profile in a Mangrove Forest. Wetlands. Vol. 29, No. 1: 16-23.

Wieder, W.R., C.C. Cleveland, and A.R. Townsend. 2009. Controls over leaf litter decomposition in wet tropical forests. Ecology 90 (12):3333-3341.

Zalamea, M., G. Gonzalez, and W.A. Gould. 2012. Comparing litterfall and standing vegetation: assessing the footprint of litterfall traps. Tropical Forests, Dr. Padmini Sudarshana (Ed.) 


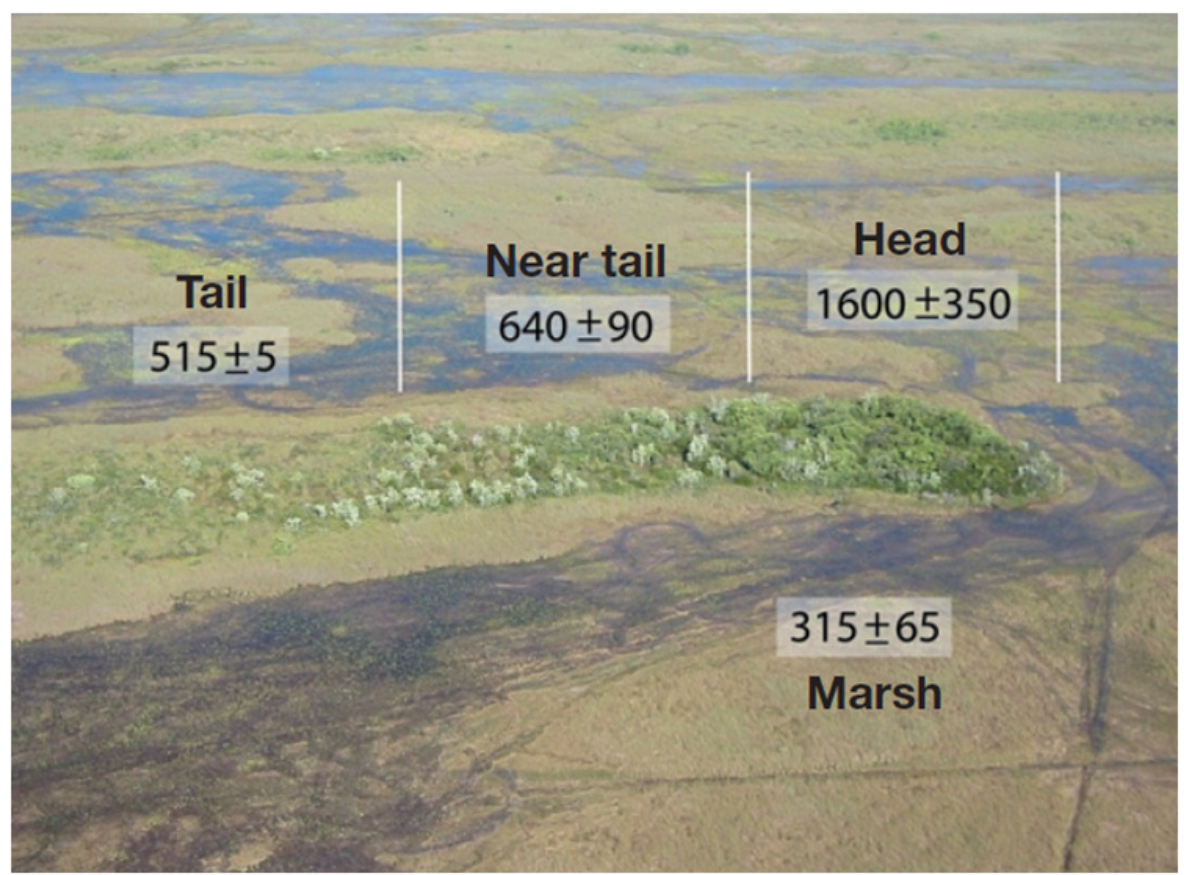

Figure 1 total phosphorus concentrations in different sections of a tree island and in the surrounding mash. Concentrations are in $\mu \mathrm{g} \mathrm{g}^{-1}$. Image from Wetzel et al., 2005.

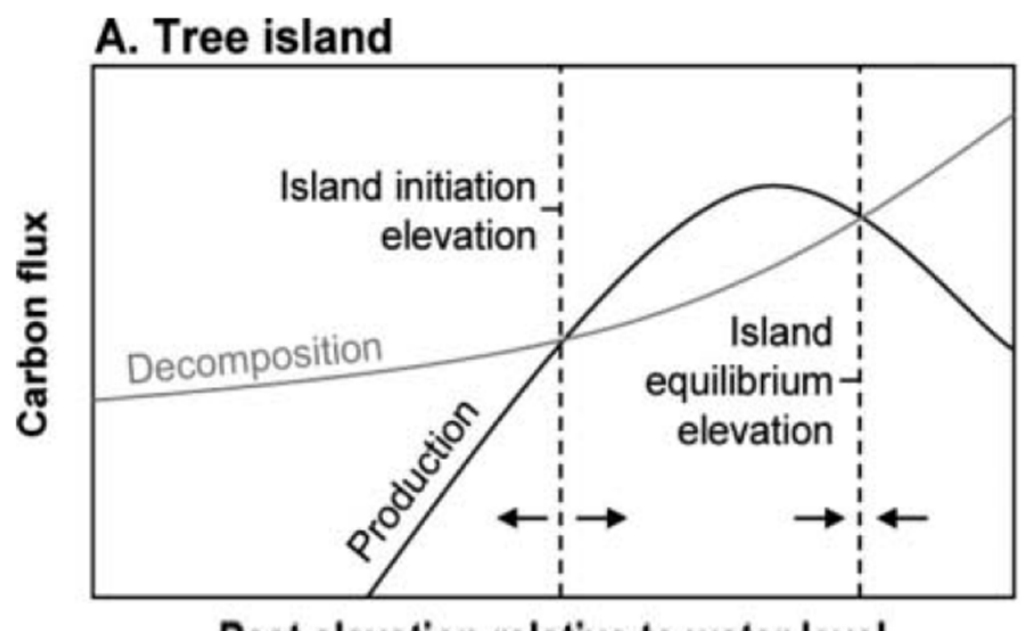

Peat elevation relative to water level

Figure 2 Peat equilibrium elevation relative to decomposition rates. Figure from Larsen et al., 2011. 


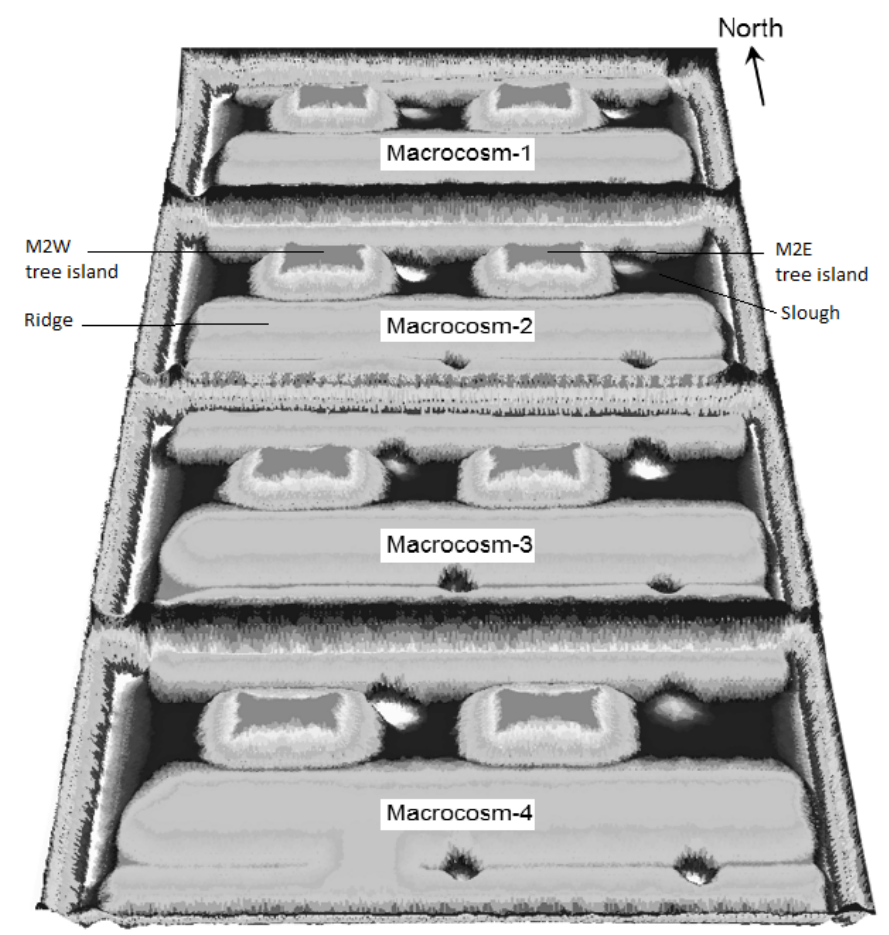

Figure 3 Diagram showing the location and components of LILA macrocosms, modified from Aich et al., 2011

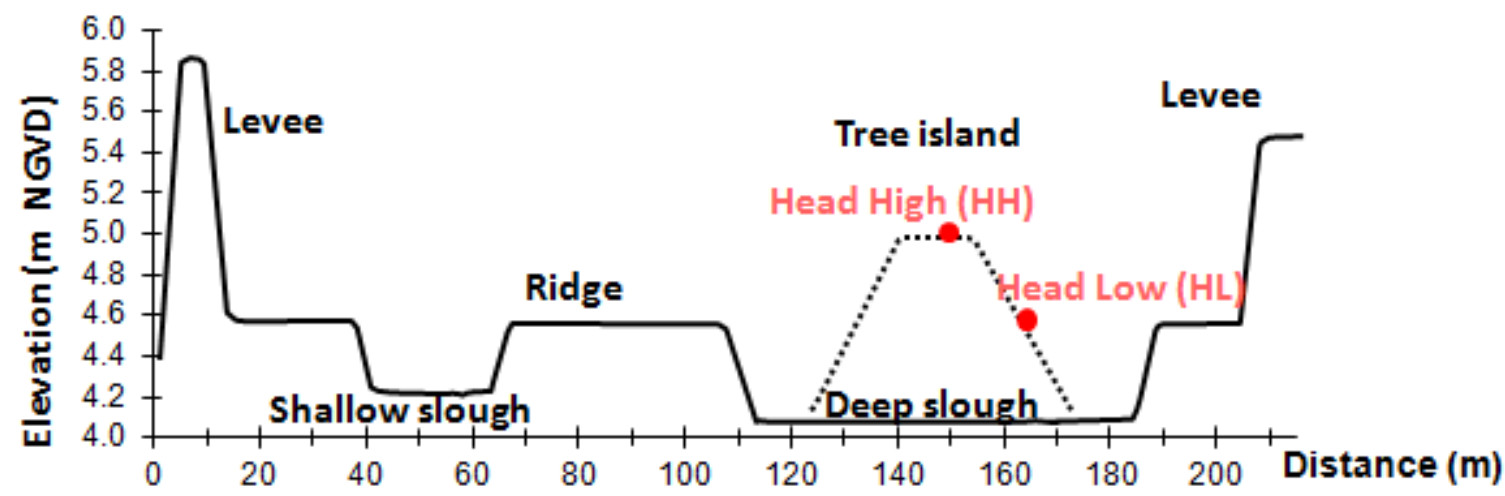

Figure 4 Cross section of a LILA macrocosm with all features and their correspondent elevations 


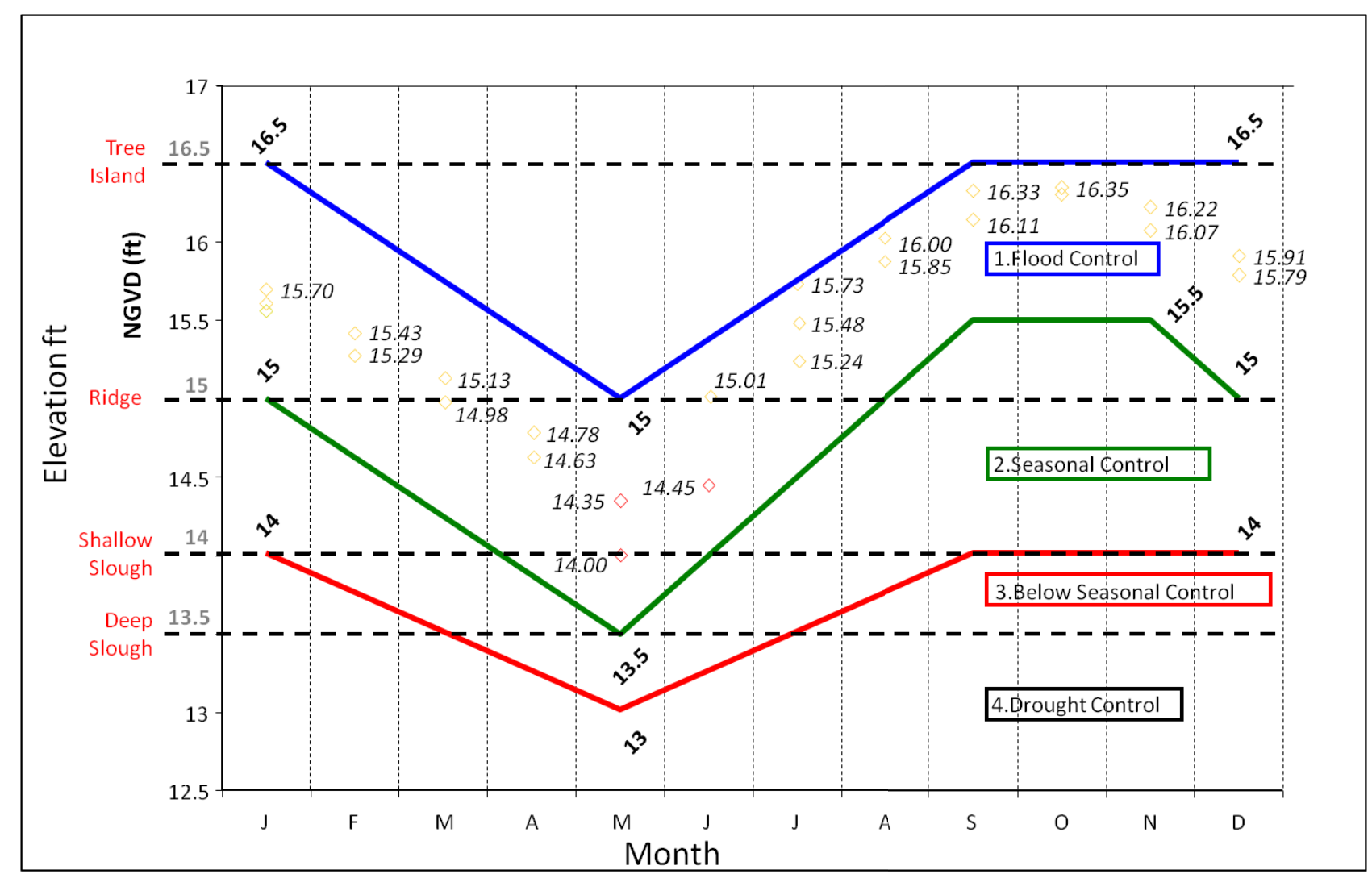

Figure 5 LILA operational hydrograph 


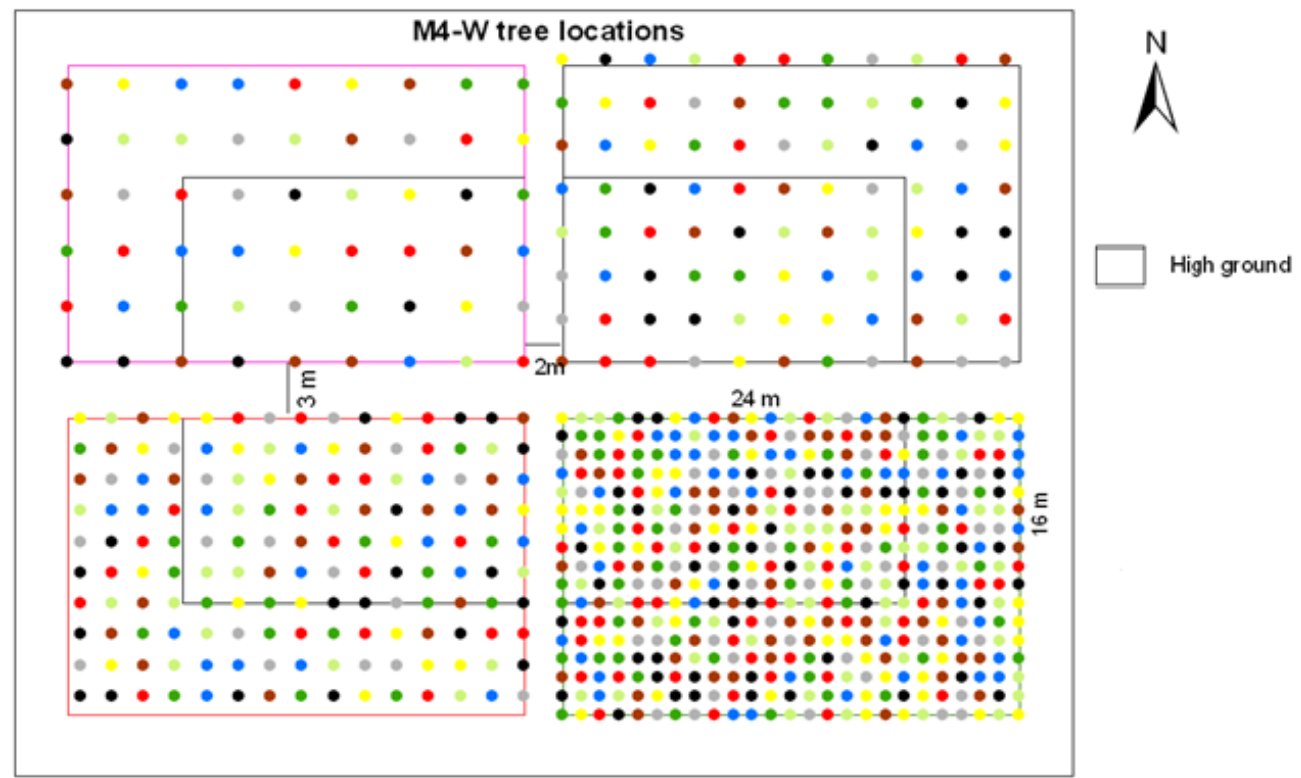

Figure 6 Diagram showing a detail of four planting densities in M4W (dots represent trees of d species)

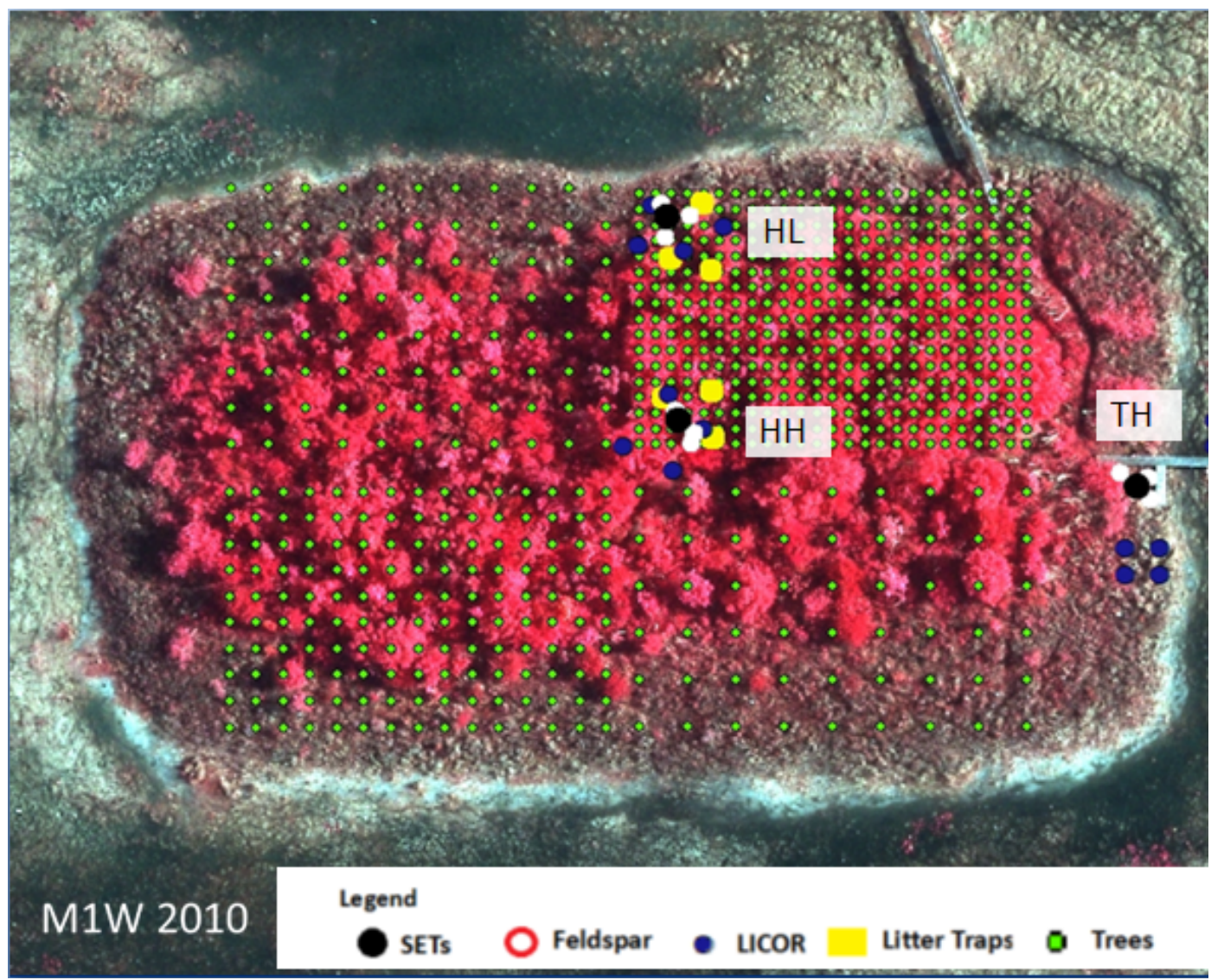

Figure 7 Aerial photograph of a LILA tree island showing the sections within the tree island, : location of the experiments. LICOR experiment is not part of this 
—M1 stage —M2 stage —M3 stage —M4 stage -HH elev. -HL elev.

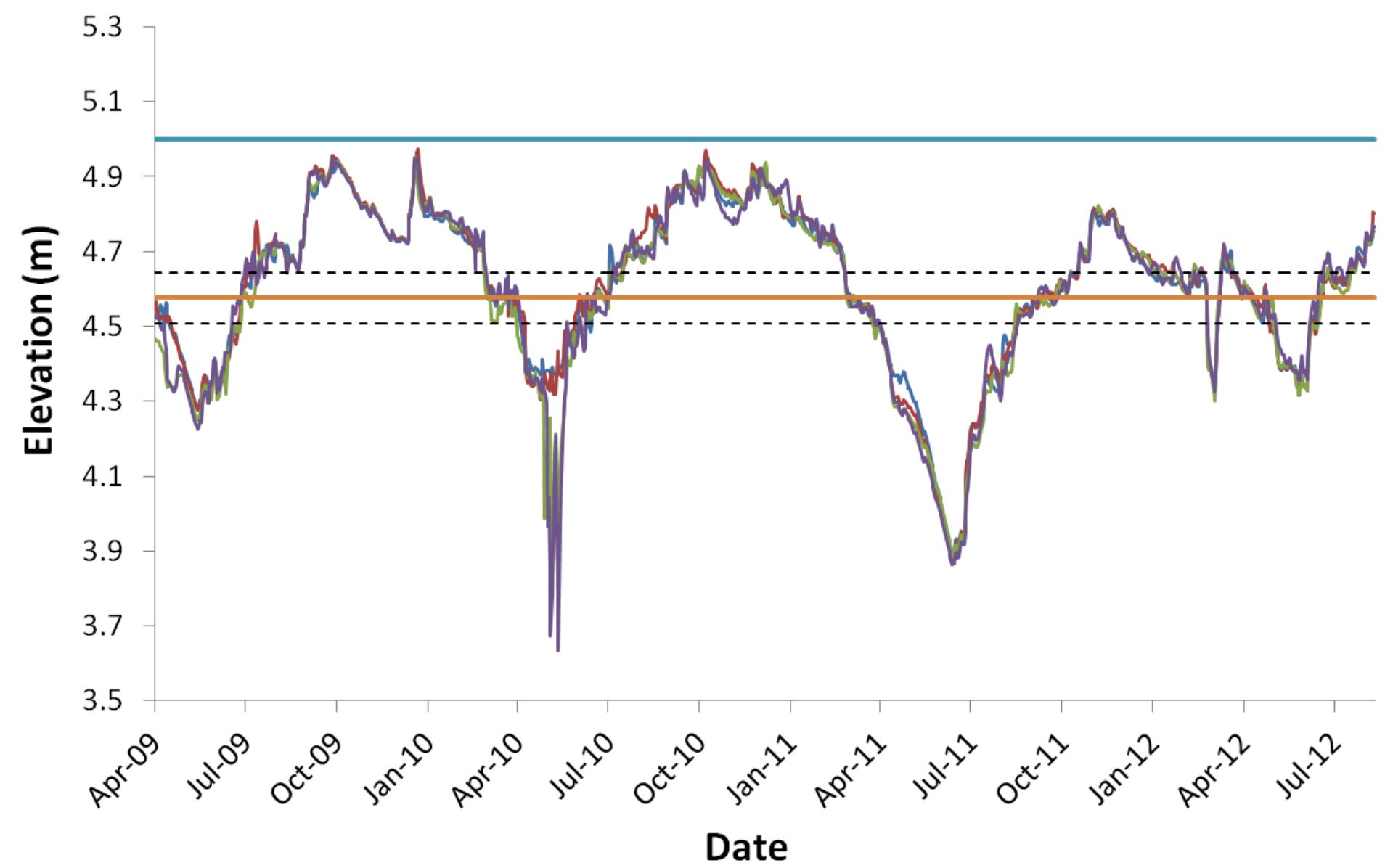

Figure 8 Hydrograph showing water levels for the four LILA macrocosms, and average elevation of the head high and head low plots from April 2009 to August 2012. Dashed lines correspond to 1 SD for the head low plots. 


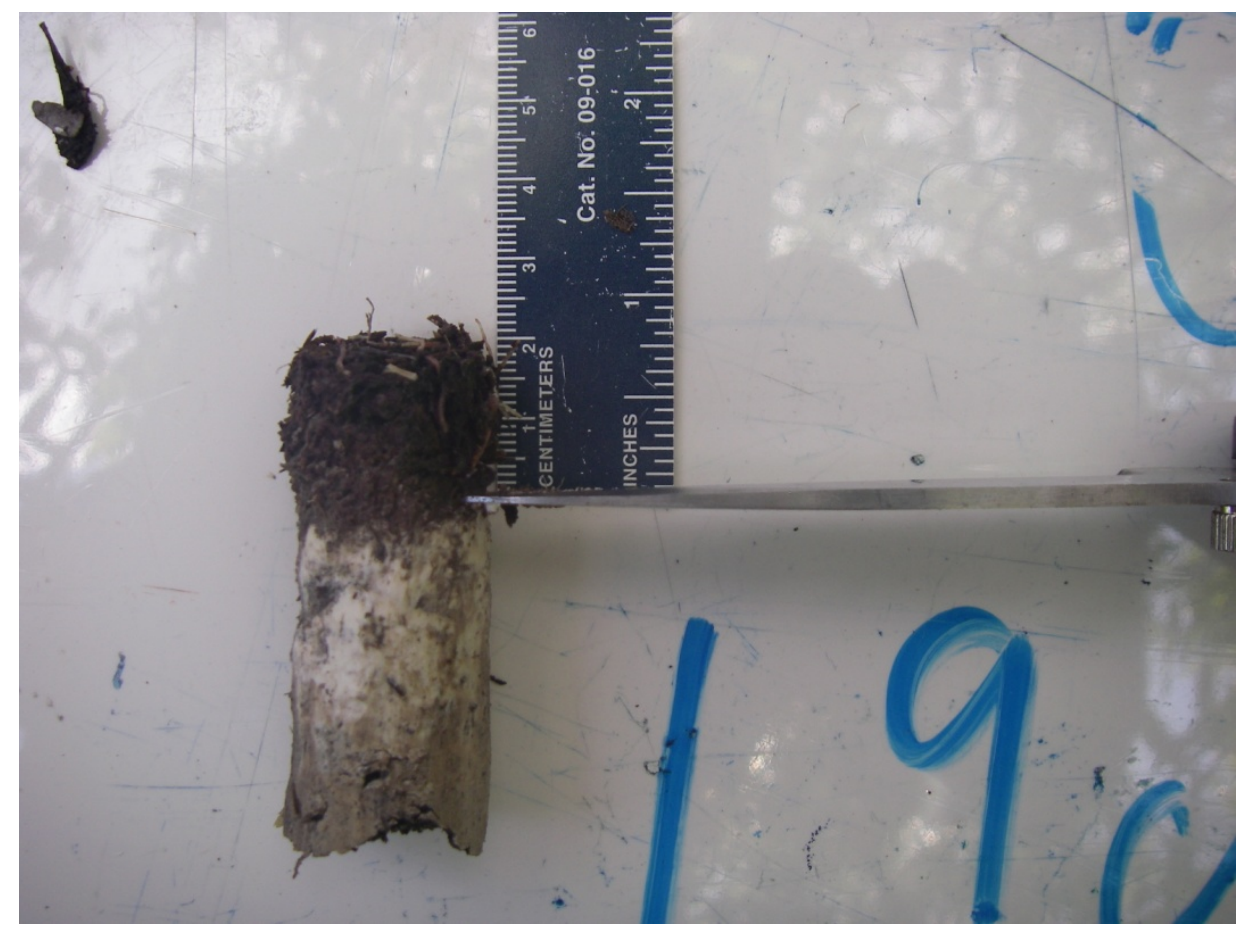

Figure 9 measurement of accretion using a feldspar marker. The amount of accreted soil is on top of the feldspar white layer.

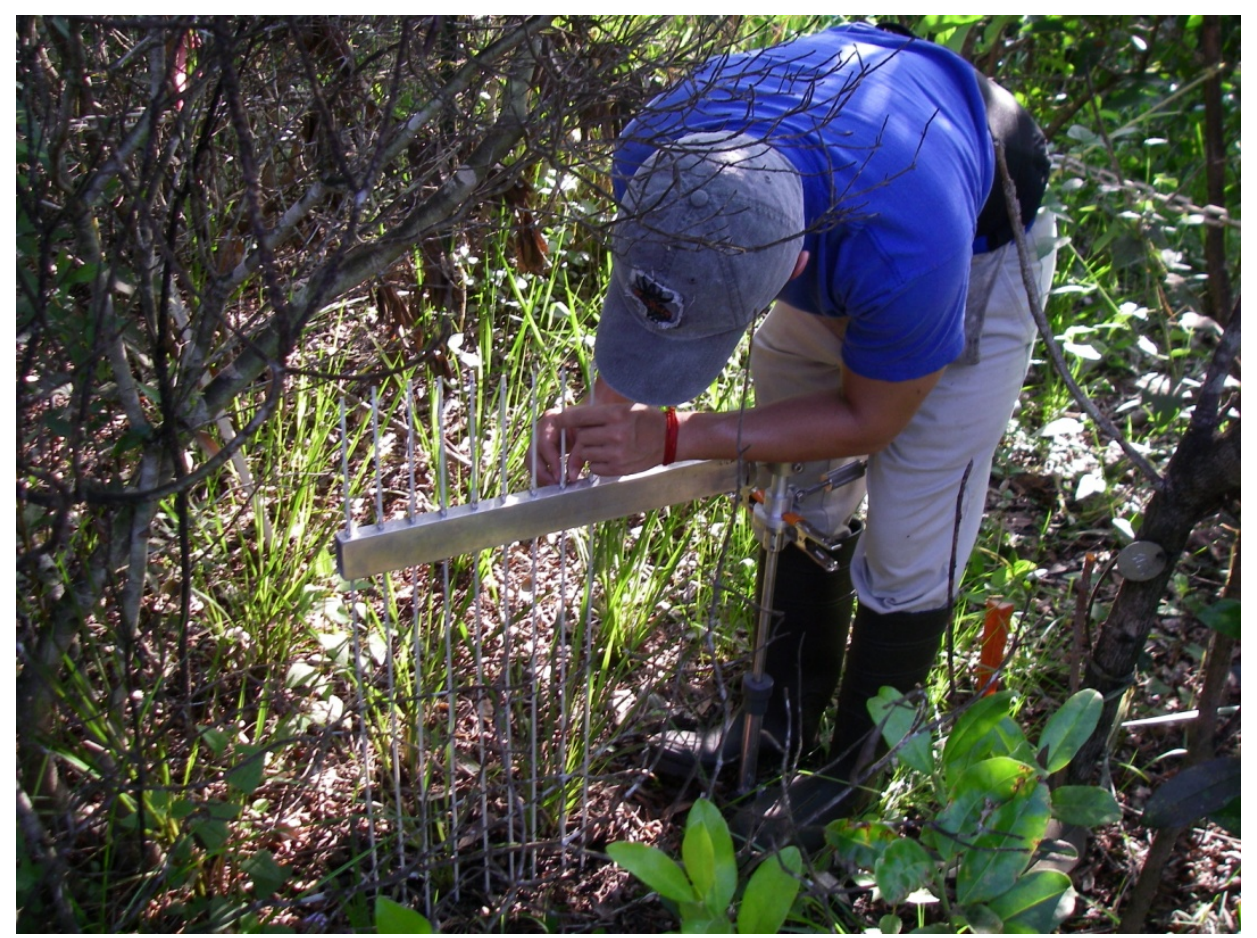

Figure 10 measurement of soil elevation using a surface elevation table (SET) in one of LILA tree islands at the high elevation in the highest density planting. 


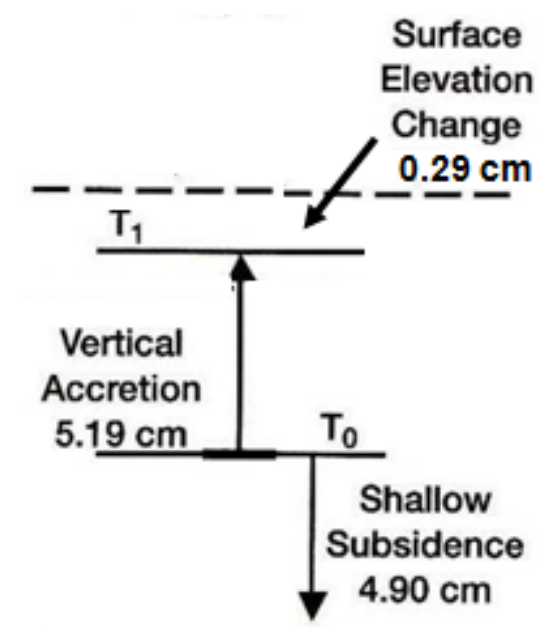

Figure 11 diagram showing an example of shallow subsidence calculation by using accretion and changes in soil elevation. 


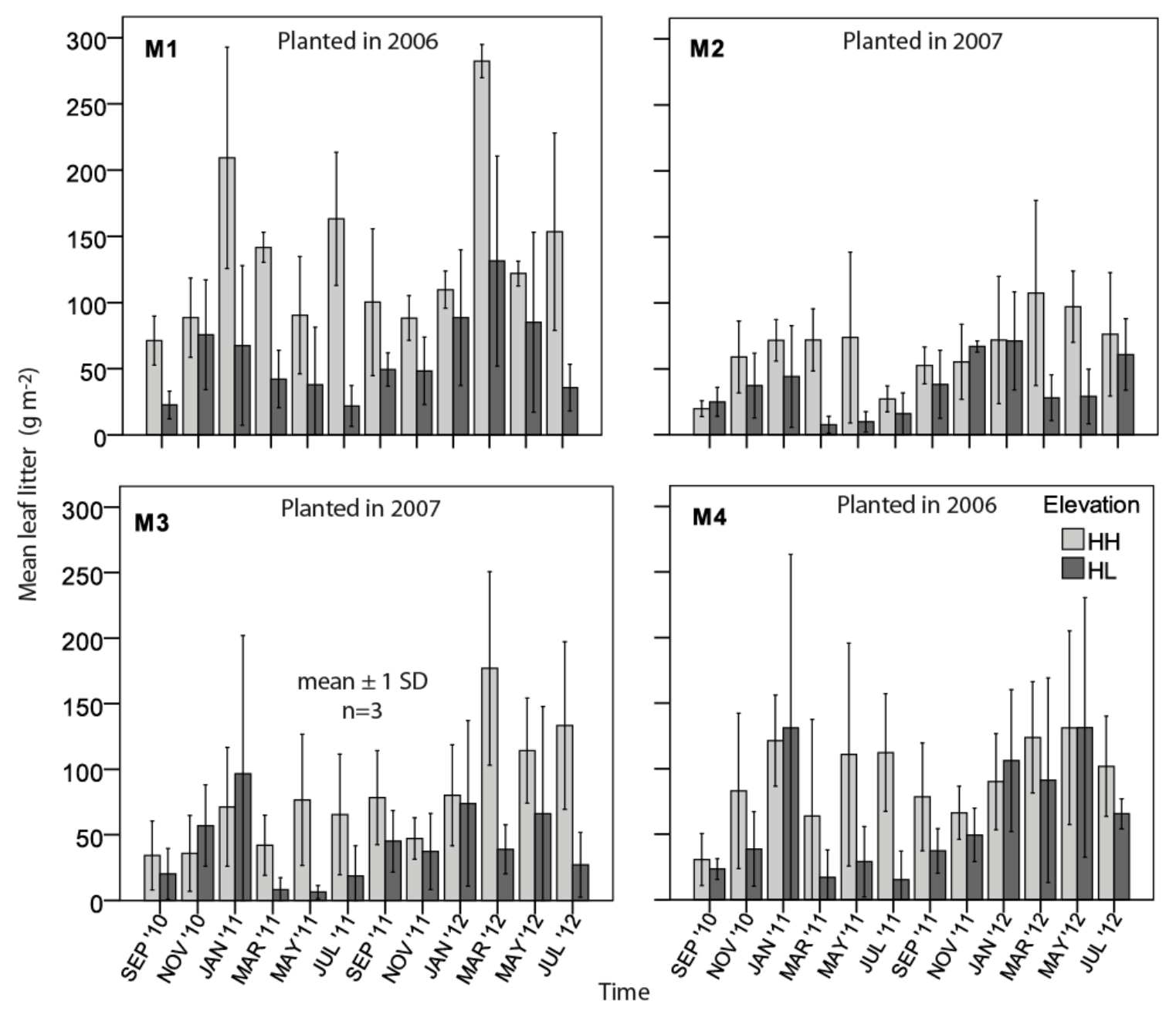

Figure 12 Mean $( \pm 1 \mathrm{SD})$ leaf litter collected in the four western tree island heads at high $(\mathrm{HH})$ and low (HL) elevations, in the highest density planting with $1 \mathrm{~m}$ spacing between trees from September 2010 to July 2012. Figure shows year of plantation of each tree islands. 


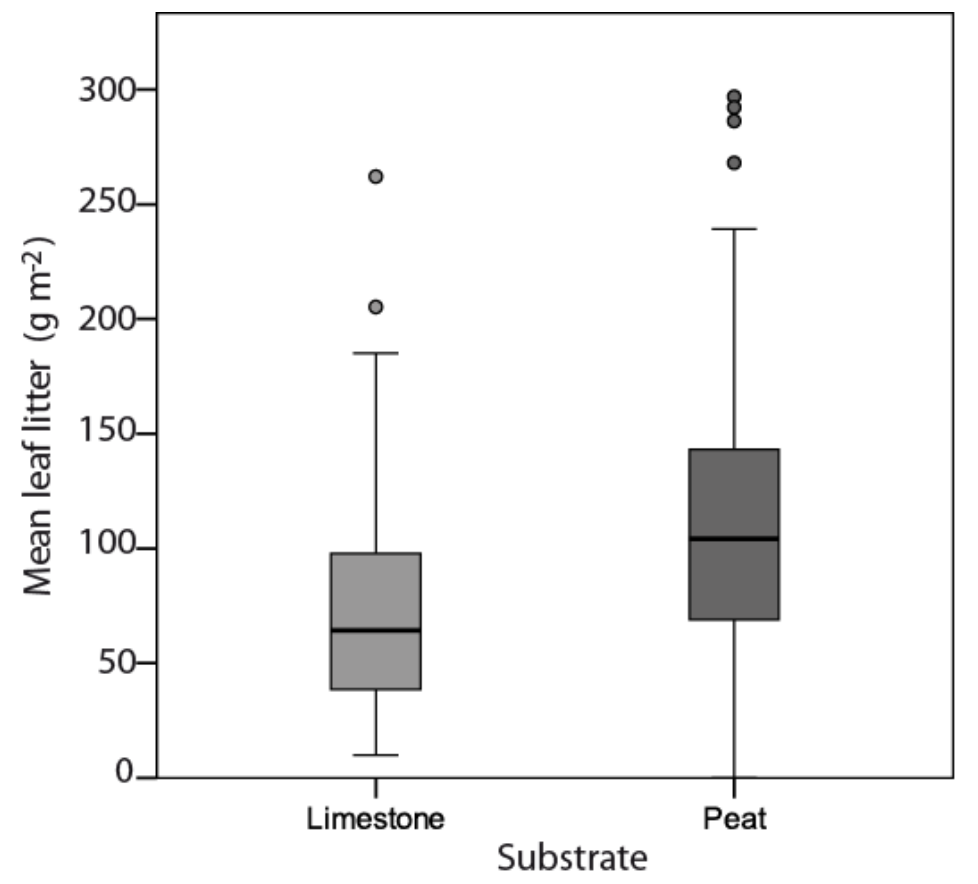

Figure 13 Litter collected at the highest density planting ( $1 \mathrm{~m}$ space between trees) in the four western tree islands combined (only in the head high locations) for different substrates from September 2010 to July 2012). 


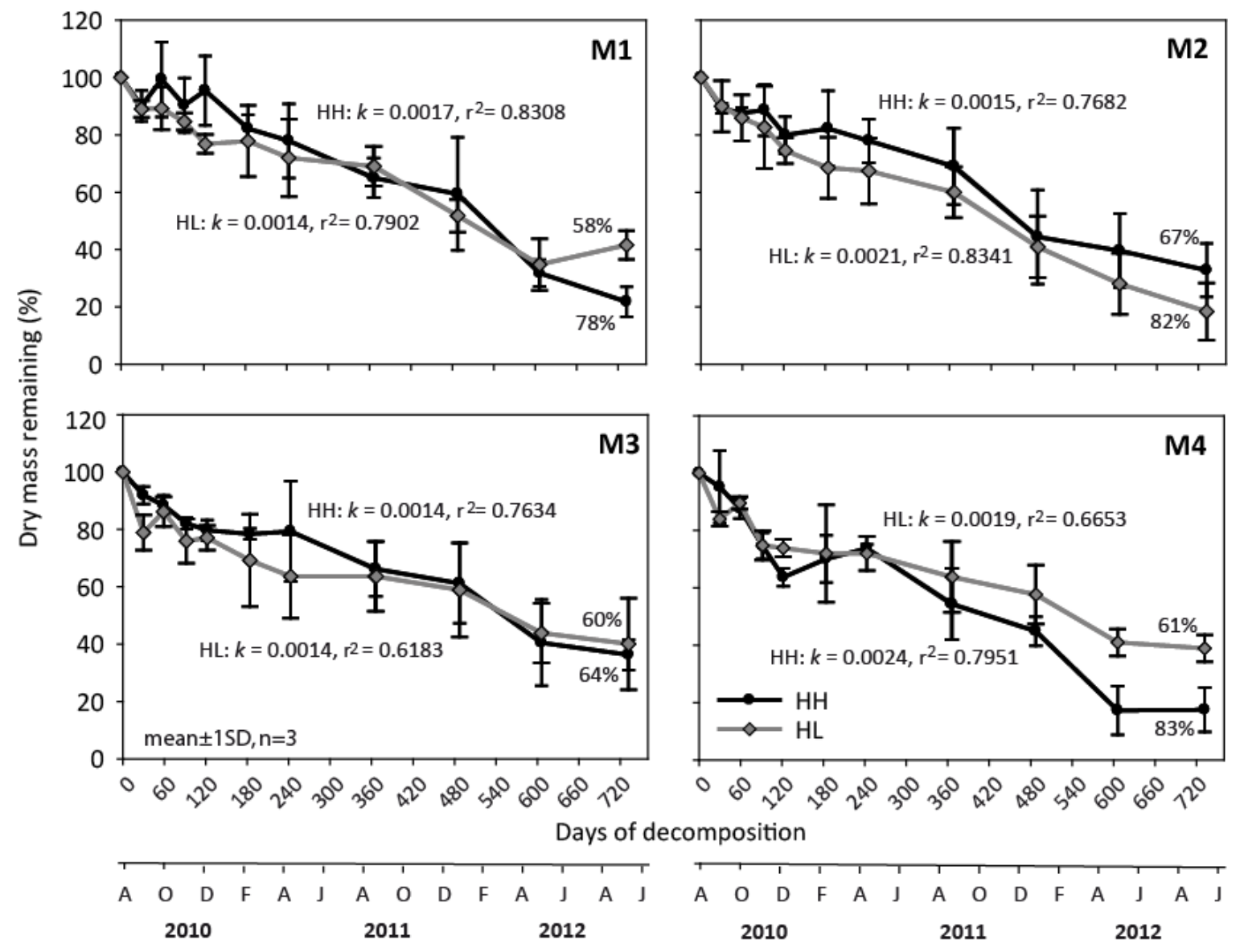

Figure 14 Decomposition expressed as percentage remaining litter mass after $732 \mathrm{~d}$ (24 mo) of decomposition in the western tree islands at high $(\mathrm{HH})$ and low (HL) elevations. Decomposition constants $\mathrm{k}(\mathrm{d}-1)$ are based on an exponential decomposition model $[\mathrm{Mt}=\mathrm{M} 0 \mathrm{e}-\mathrm{kt}$, where $\mathrm{Mt}$ is the mass remaining at time $\mathrm{t}$ and $\mathrm{M} 0$ is the initial mass] and $\mathrm{r} 2$ from regression analysis. Values are mean $\pm 1 \mathrm{SD}$ from triplicate bags $(\mathrm{n}=3)$. Percentages of mass loss after $732 \mathrm{~d}(24 \mathrm{mo})$ of decomposition are also showed. 


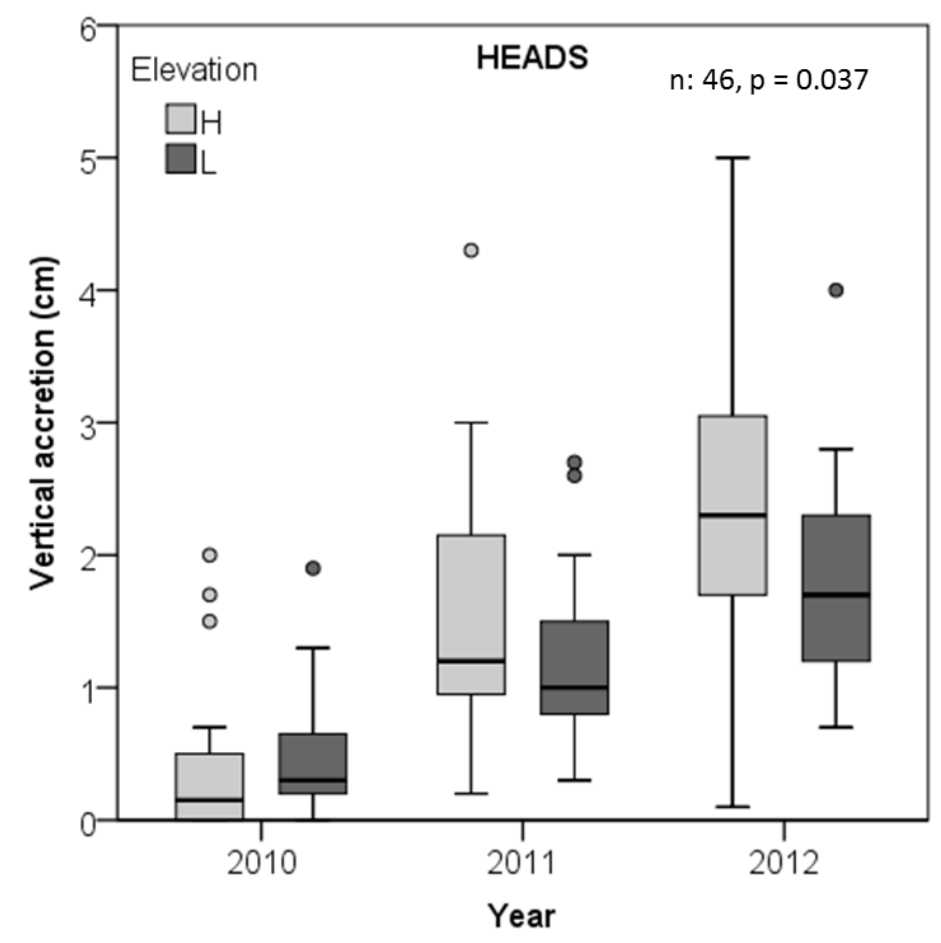

Figure 15 Soil accreting one (2010), two (2011), and three (2012) years after 2009 initial measurements above feldspar markers located at high (Head High, HH) and low elevations (Head Low) at the heads of eight tree islands combined.

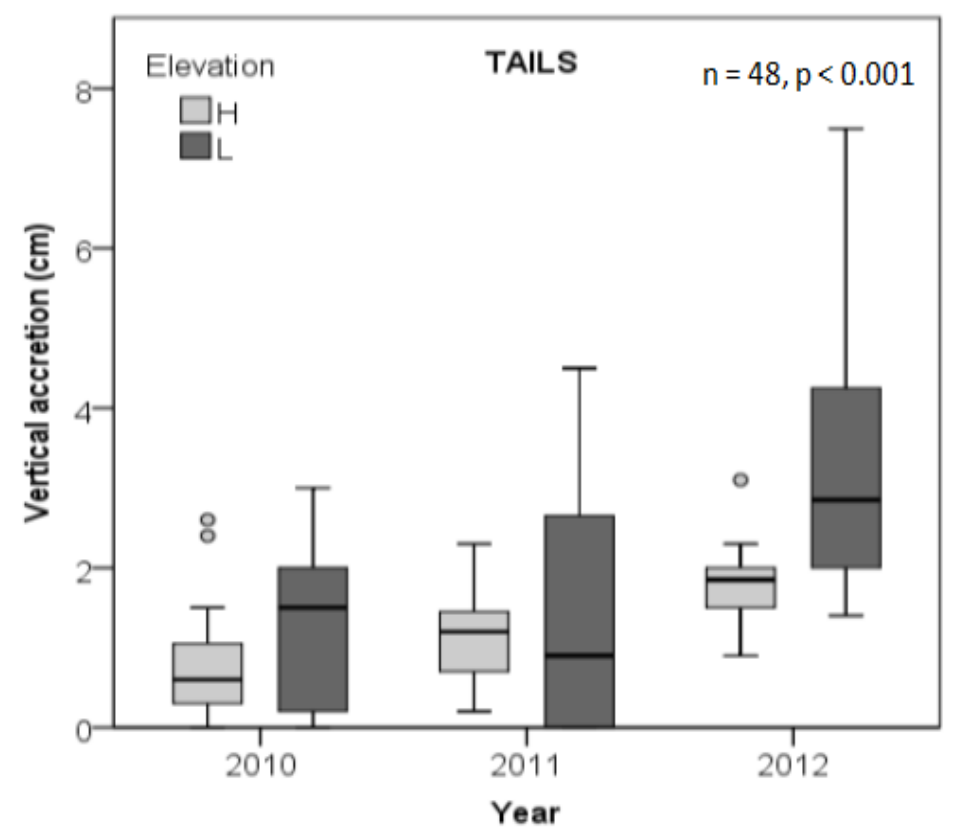

Figure 16 Sediment accreting one (2010), two (2011), and three (2012) years after 2009 initial measurements above feldspar markers located at the mid-slope (Tail High) and at the base (Tail Low) of eight tree islands tails combined. 


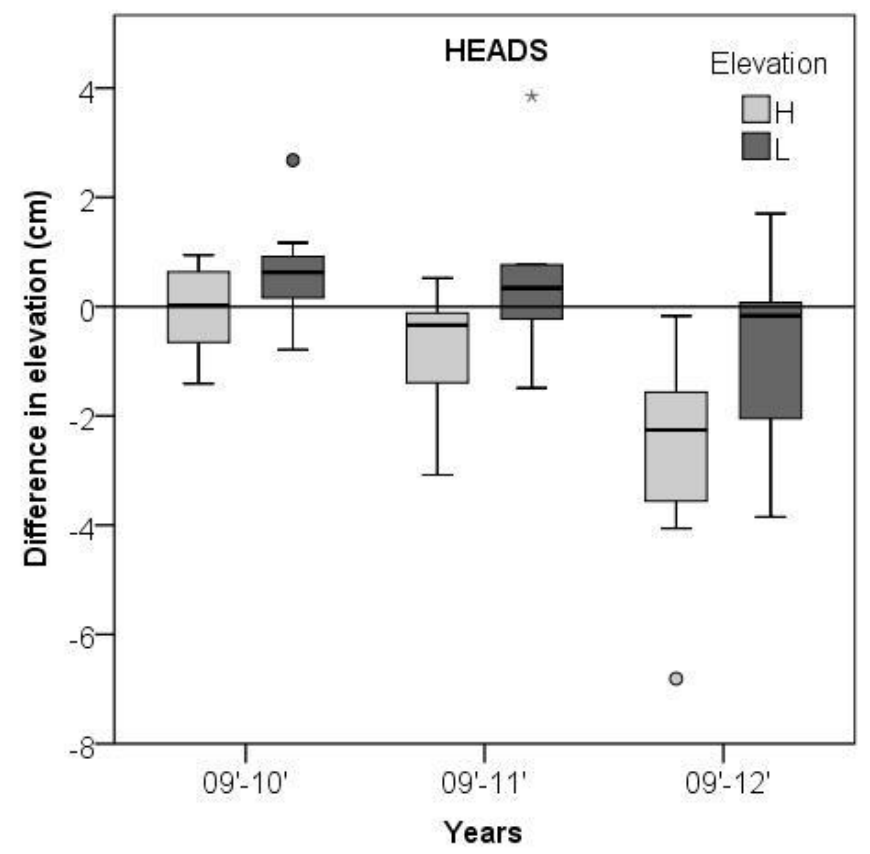

Figure 17 Surface elevation table (SET) elevation differences one (2010), two (2011), and three (2012) years after 2009 initial measurements at high (Head High) and low elevation (Head Low) of heads of eight tree islands combined.

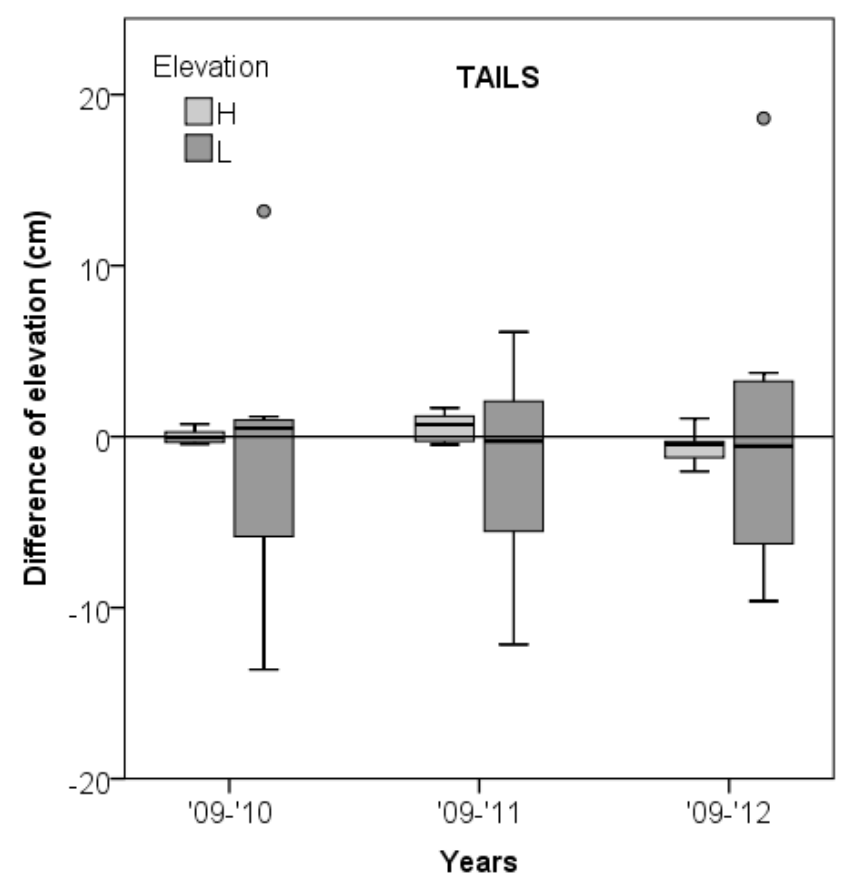

Figure 18 Surface elevation table (SET) elevation differences between 2009 initial measurements and subsequent years 2010, 2011 and 2012 data $(n=8)$ at mid-slope (Tail High, TH) and at the base of the tail slope (Tail Low, TL) of eight tree islands combined. 


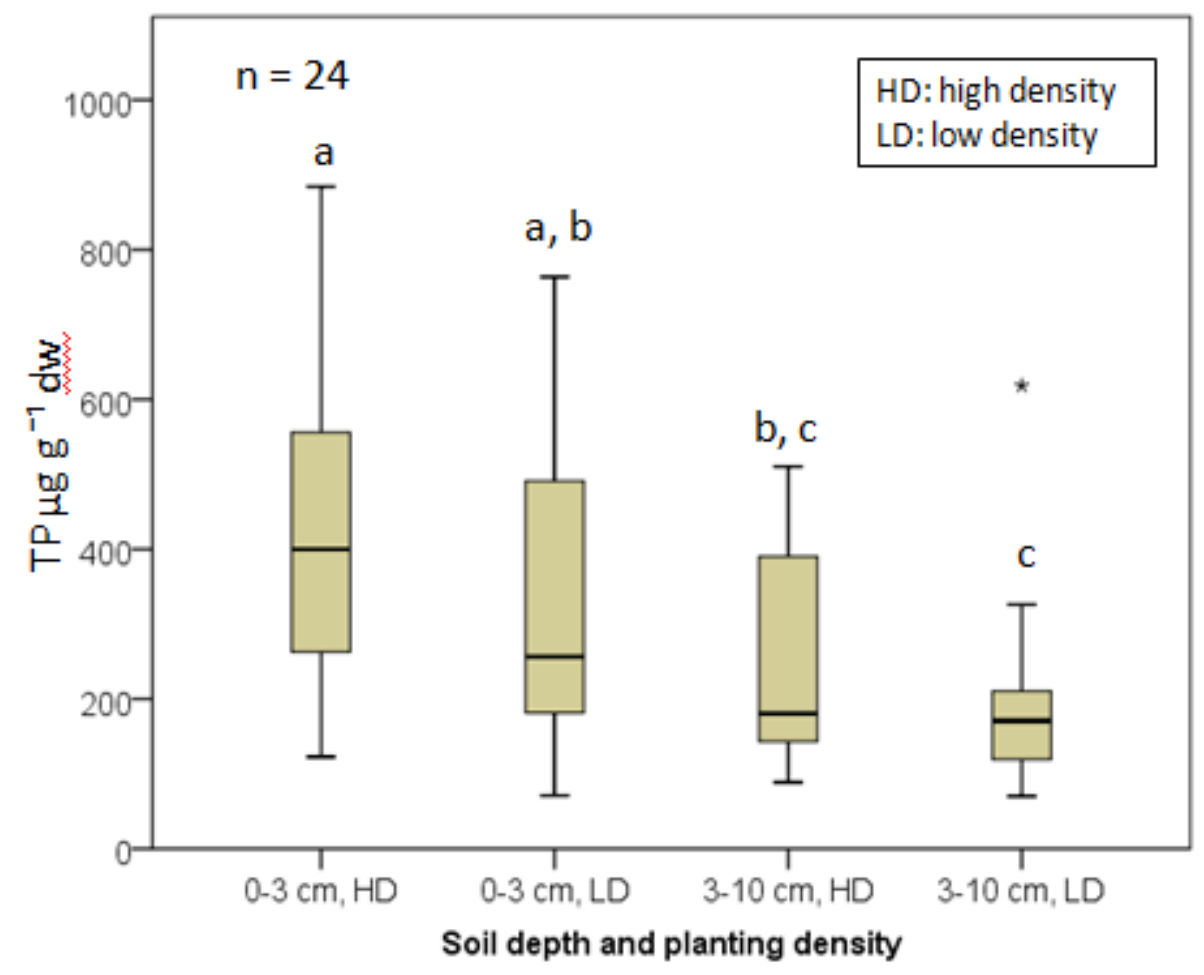

Figure 19 Total phosphorus concentrations for combinations of soil depth and planting density. All islands combined, all elevations combined. Letters correspond to groups according to Tukey HSD Post Hoc comparisons. 


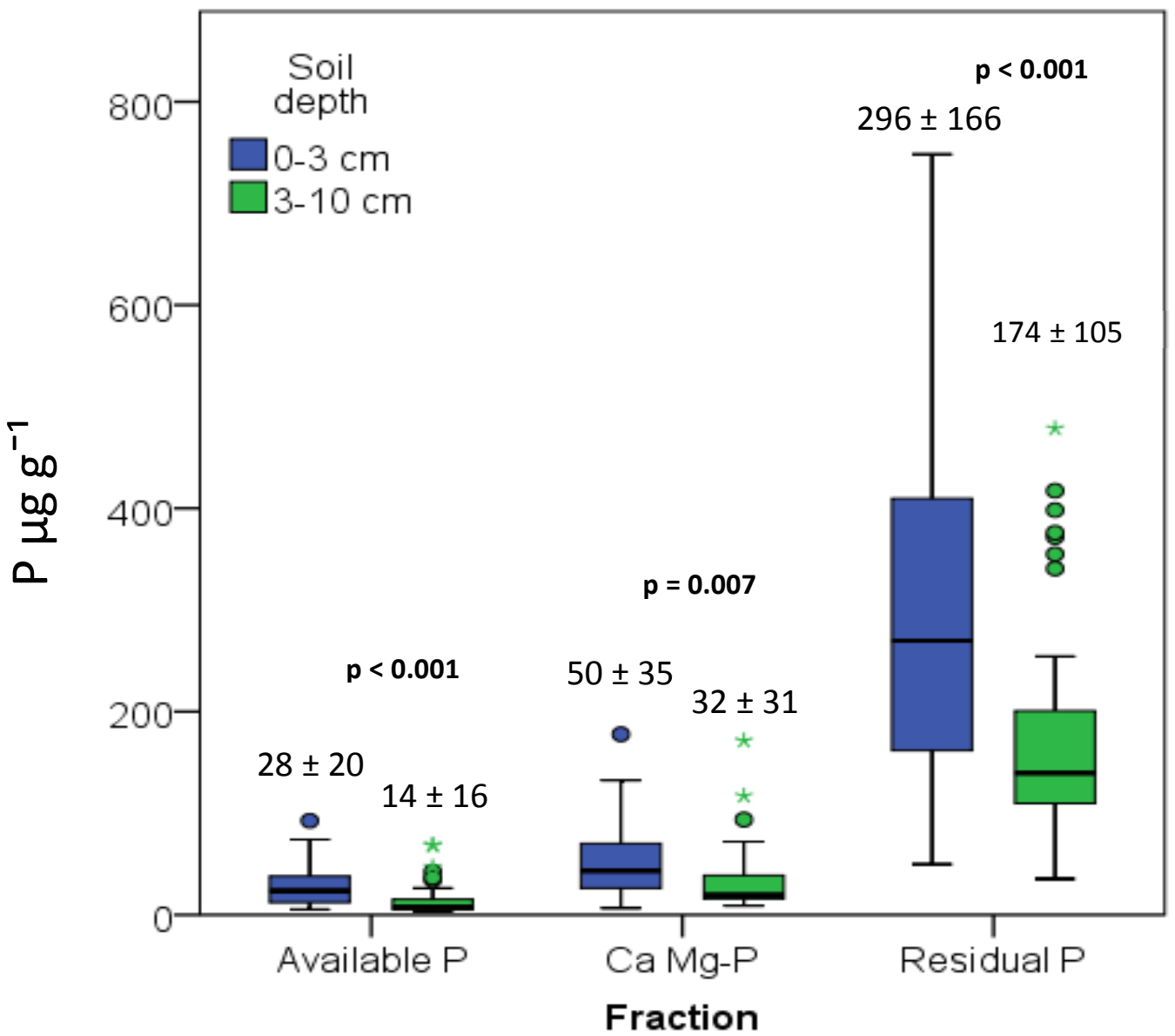

Figure 20 Concentration of $\mathrm{P}$ fractions for two soil increments top $(0-3 \mathrm{~cm})$, and bottom $(3-10 \mathrm{~cm}) . \mathrm{n}=48$. Values are means $+/$ - SD. $p$ values correspond to independent samples t-tests between soil increments. 


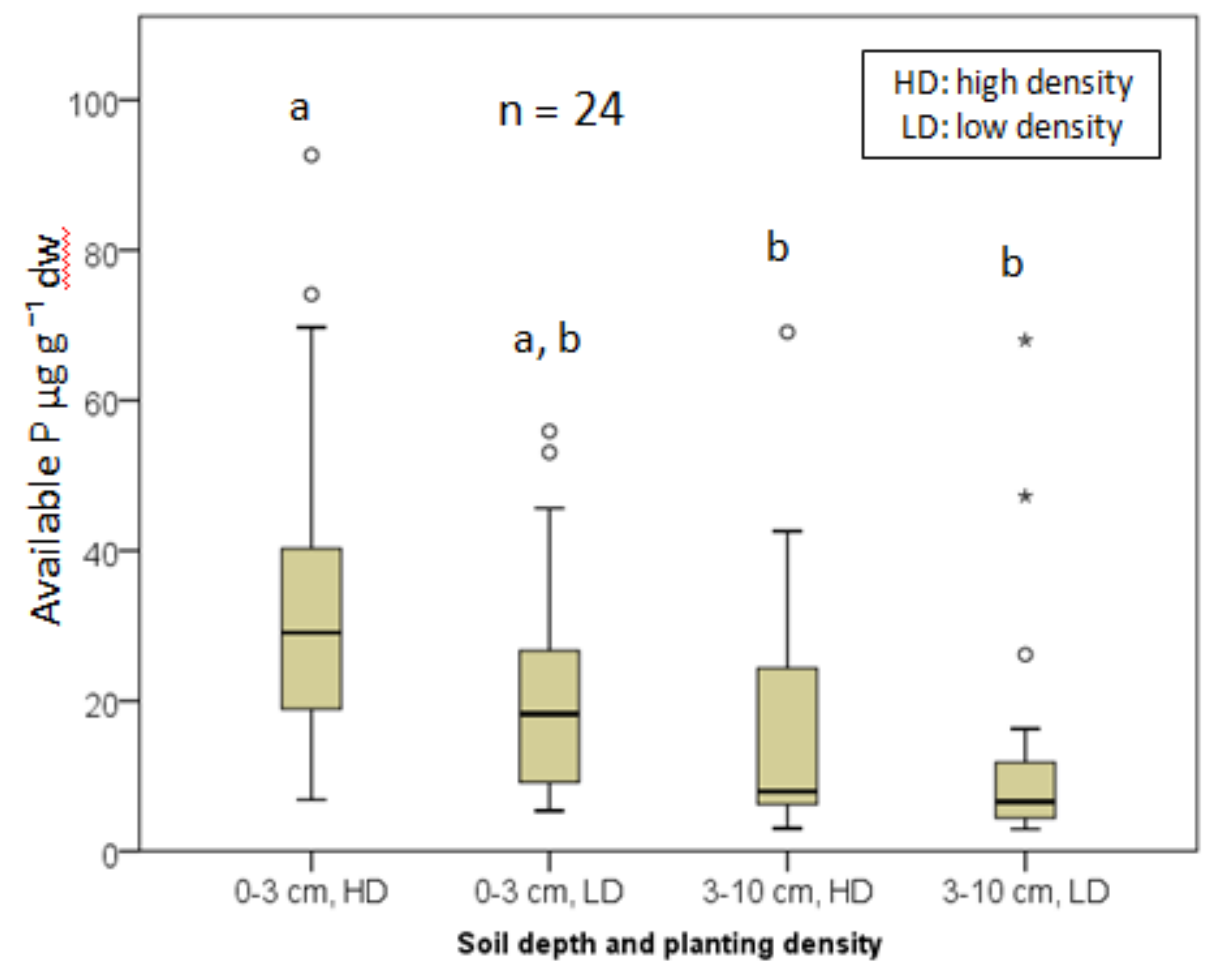

Figure 21 Available phosphorus concentration for combinations of soil depth and planting density. All islands combined, all elevations combined. Letters correspond to groups according to Dunnett C Post Hoc comparisons. 
Table 1 Rates of annual litter production estimated from litter traps at high and low elevations, $n=24$, and peat and limestone substrates, $n=12$.

\begin{tabular}{|c|c|c|c|c|c|}
\hline Parameter & Unit & \multicolumn{2}{|c|}{ Elevation } & \multicolumn{2}{c|}{ Substrate } \\
\hline & & High & Low & Peat & Limestone \\
\hline Litter & $\mathrm{g} \mathrm{m}^{-2} \mathrm{y}^{-1}$ & $559 \pm 235$ & $308 \pm 188$ & $684 \pm 215$ & $435 \pm 187$ \\
\hline
\end{tabular}

Values represent mean +/- 1 SD. For high and low elevation rates all traps were used, while for peat and limestone substrate only high elevations were used.

Table 2 Rates of accretion, change in elevation, and shallow subsidence for high and low elevation at the head of all eight tree islands, $n=8$.

\begin{tabular}{|c|c|c|c|}
\hline Elevation & Accretion & Change in elevation & Shallow subsidence \\
\hline & $\mathrm{cm} \mathrm{v}^{-1}$ & $\mathrm{~cm} \mathrm{v}^{-1}$ & $\mathrm{~cm} \mathrm{v}^{-1}$ \\
\hline $\mathrm{HH}$ & $0.78 \pm 0.13$ & $-0.69 \pm 0.35$ & 1.47 \\
\hline $\mathrm{HL}$ & $0.60 \pm 0.41$ & $-0.063 \pm 0.36$ & 0.663 \\
\hline
\end{tabular}

Accretion and change in elevation values are means $+/-1 \mathrm{SE}$, means were calculated by regression analysis. Shallow subsidence $=$ accretion - change in elevation . 
Table 3 Pearson correlation for soil characteristics using two increments and all islands combined, $\mathrm{n}=95$.

\begin{tabular}{|c|c|c|c|c|c|c|c|c|c|}
\hline Parameter (units) & $\mathrm{pH}$ & FBD $\left(\mathrm{gdw} \mathrm{cm}^{-3}\right)$ & $\mathrm{TP}\left(\mu \mathrm{g} \mathrm{g}^{-1} \mathrm{dw}\right)$ & $\mathrm{OM}\left(\mathrm{g} \mathrm{g}^{-1} \mathrm{dw}\right)$ & $\mathrm{TN}\left(\mathrm{mg} \mathrm{g}^{-1} \mathrm{dw}\right)$ & $\mathrm{TC}\left(\mathrm{mg} \mathrm{g}^{-1} \mathrm{dw}\right)$ & $\mathrm{C}: \mathrm{N}$ & $C: P$ & $\mathrm{~N}: \mathrm{P}$ \\
\hline FBD $\left(\mathrm{gdw} \mathrm{cm}^{-3}\right)$ & $.498^{* *}$ & & & & & & & & \\
\hline $\mathrm{TP}\left(\mu \mathrm{g} \mathrm{g}^{-1} \mathrm{dw}\right)$ & $-.370^{* *}$ & $-.791^{* *}$ & & & & & & & \\
\hline $\mathrm{OM}\left(\mathrm{gg}^{-1} \mathrm{dw}\right)$ & $-.501^{* *}$ & $-.824^{* *}$ & $.905^{* *}$ & & & & & & \\
\hline $\mathrm{TN}\left(\mathrm{mg} \mathrm{g}^{-1} \mathrm{dw}\right)$ & $-.343^{* *}$ & $-.773^{* *}$ & $.888^{* *}$ & $.904^{* *}$ & & & & & \\
\hline $\mathrm{TC}\left(\mathrm{mg} \mathrm{g}^{-1} \mathrm{dw}\right)$ & $-.353^{* *}$ & $-.768^{* *}$ & $.875^{* *}$ & $.899^{* *}$ & $.991^{* *}$ & & & & \\
\hline $\mathrm{C}: \mathrm{N}$ & -.162 & -.111 & .109 & .146 & .150 & $.267^{* *}$ & & & \\
\hline $\mathrm{C}: \mathrm{P}$ & .138 & $.368^{* *}$ & $-.450^{* *}$ & $-.287^{* *}$ & -.089 & -.060 & $.251^{*}$ & & \\
\hline $\mathrm{N}: \mathrm{P}$ & .180 & $.399^{* *}$ & $-.496^{* *}$ & $-.330^{* *}$ & -.125 & -.121 & .025 & $.969^{* *}$ & \\
\hline $\mathrm{TP}\left(\mu \mathrm{g} \mathrm{cm}^{-3}\right)$ & .063 & -.007 & $.358^{* *}$ & .125 & .167 & .181 & .135 & $-.362^{* *}$ & $-.413^{* *}$ \\
\hline
\end{tabular}

** Significant at 0.01 level, * significant at 0.05 level. 
Table 4 Independent samples t tests results for soils separated in two soil increments, all four islands, and both planting densities combined. Values are means +/- SD. $(\mathrm{n}=48)$.

\begin{tabular}{|c|c|c|c|}
\hline Parameter (Unit) & \multicolumn{2}{|c|}{ Soil depth } & $\mathrm{p}$ value \\
\hline & $0-3 \mathrm{~cm}$ & $3-10 \mathrm{~cm}$ & \\
\hline $\mathrm{pH}$ & $7.28 \pm 0.42$ & $7.28 \pm 0.39$ & 0.998 \\
\hline FBD $\left(\mathrm{gdw} \mathrm{cm}^{-3}\right)$ & $0.45 \pm 0.22$ & $0.73 \pm 0.33$ & $<0.001$ \\
\hline $\mathrm{TP}\left(\mu \mathrm{g} \mathrm{g}^{-1} \mathrm{dw}\right)$ & $374 \pm 202$ & $216 \pm 134$ & $<0.001$ \\
\hline $\mathrm{TP}\left(\mu \mathrm{g} \mathrm{cm}^{-3}\right)$ & $135 \pm 56$ & $122 \pm 38$ & 0.362 \\
\hline $\mathrm{TN}\left(\mathrm{m} \mathrm{g} \mathrm{g}^{-1} \mathrm{dw}\right)$ & $14.4 \pm 6.8$ & $10.2 \pm 5.7$ & 0.002 \\
\hline $\mathrm{TC}\left(\mathrm{mg} \mathrm{g}^{-1} \mathrm{dw}\right)$ & $190 \pm 90$ & $132 \pm 75$ & 0.002 \\
\hline $\mathrm{C}: \mathrm{N}$ & $15.3 \pm 1.1$ & $15.2 \pm 1.1$ & 0.487 \\
\hline $\mathrm{C}: \mathrm{P}$ & $1401 \pm 327$ & $1710 \pm 653$ & 0.007 \\
\hline $\mathrm{N}: \mathrm{P}$ & $91 \pm 21$ & $113 \pm 40$ & 0.001 \\
\hline $\mathrm{OM}\left(\mathrm{g} \mathrm{g}^{-1} \mathrm{dw}\right)$ & $0.36 \pm 0.19$ & $0.25 \pm 0.18$ & 0.007 \\
\hline & & & \\
\hline
\end{tabular}

Table 5 Independent samples t tests results for top soils $(0-3 \mathrm{~cm})$ separated in high and low elevations, only in peat substrate, both planting densities combined. Values are means $+/$ SD. High elevation $n=12$, low elevation $n=24$.

\begin{tabular}{|c|c|c|c|}
\hline Parameter (unit) & \multicolumn{2}{|c|}{ Elevation } & $\mathrm{p}$ value \\
\hline & High & Low & \\
\hline $\mathrm{pH}$ & $7.09 \pm 0.20$ & $7.10 \pm 0.20$ & 0.084 \\
\hline $\mathrm{FBD}\left(\mathrm{gdw} \mathrm{cm}^{-3}\right)$ & $0.47 \pm 0.13$ & $0.36 \pm 0.20$ & 0.059 \\
\hline $\mathrm{TP}\left(\mu \mathrm{g} \mathrm{g}^{-1} \mathrm{dw}\right)$ & $398 \pm 103$ & $430 \pm 239$ & 0.586 \\
\hline $\mathrm{TP}\left(\mu \mathrm{g} \mathrm{cm}^{-3}\right)$ & $184 \pm 76$ & $114 \pm 29$ & 0.003 \\
\hline $\mathrm{TN}\left(\mathrm{m} \mathrm{g} \mathrm{g}^{-1} \mathrm{dw}\right)$ & $15.0 \pm 2.7$ & $16.0 \pm 8.3$ & 0.574 \\
\hline $\mathrm{TC}\left(\mathrm{mg} \mathrm{g}^{-1} \mathrm{dw}\right)$ & $210 \pm 45$ & $208 \pm 108$ & 0.933 \\
\hline $\mathrm{C}: \mathrm{N}$ & $16.3 \pm 0.9$ & $15.1 \pm 0.9$ & 0.001 \\
\hline $\mathrm{C}: \mathrm{P}$ & $1409 \pm 287$ & $1336 \pm 355$ & 0.399 \\
\hline $\mathrm{N}: \mathrm{P}$ & $87 \pm 19$ & $88 \pm 22$ & 0.808 \\
\hline $\mathrm{OM}\left(\mathrm{g} \mathrm{g}^{-1} \mathrm{dw}\right)$ & $0.35 \pm 0.20$ & $0.43 \pm 0.22$ & 0.124 \\
\hline & & & \\
\hline
\end{tabular}


Table 6 Independent samples $\mathrm{T}$ tests results for top soils $(0-3 \mathrm{~cm})$ separated in limestone and peat substrates only in high elevations, both planting densities combined. Values are means +/- SD., $\mathrm{n}=12$.

\begin{tabular}{|c|c|c|c|}
\hline Parameter (unit) & \multicolumn{2}{|c|}{ Substrate } & $\mathrm{p}$ value \\
\hline & Limestone & Peat & \\
\hline $\mathrm{pH}$ & $7.57 \pm 0.56$ & $7.35 \pm 0.45$ & 0.306 \\
\hline $\mathrm{FBD}\left(\mathrm{gdw} \mathrm{cm}^{-3}\right)$ & $0.64 \pm 0.24$ & $0.47 \pm 0.13$ & 0.045 \\
\hline $\mathrm{TP}\left(\mu \mathrm{g} \mathrm{g}^{-1} \mathrm{dw}^{-}\right)$ & $238 \pm 134$ & $398 \pm 103$ & 0.003 \\
\hline $\mathrm{TP}\left(\mu \mathrm{g} \mathrm{cm}^{-3}\right)$ & $129 \pm 45$ & $184 \pm 76$ & 0.031 \\
\hline $\mathrm{TN}\left(\mathrm{mg} \mathrm{g}^{-1} \mathrm{dw}\right)$ & $10.5 \pm 4.9$ & $15.0 \pm 2.7$ & 0.012 \\
\hline $\mathrm{TC}\left(\mathrm{mg} \mathrm{g}^{-1} \mathrm{dw}\right)$ & $135 \pm 64$ & $210 \pm 45$ & 0.003 \\
\hline $\mathrm{C}: \mathrm{N}$ & $14.8 \pm 1.1$ & $16.3 \pm 0.9$ & 0.001 \\
\hline $\mathrm{C}: \mathrm{P}$ & $1523 \pm 292$ & $1409 \pm 287$ & 0.322 \\
\hline $\mathrm{N}: \mathrm{P}$ & $103 \pm 18$ & $87 \pm 19$ & 0.045 \\
\hline $\mathrm{OM}\left(\mathrm{g} \mathrm{g}^{-1} \mathrm{dw}\right)$ & $0.22 \pm 0.13$ & $0.35 \pm 0.95$ & 0.012 \\
\hline
\end{tabular}

Table 7 Independent samples $\mathrm{T}$ tests results for top soils separated in planting densities, both elevations combined. Values are means $+/-$ SD., $n=24$.

\begin{tabular}{|c|c|c|c|}
\hline Parameter (units) & \multicolumn{3}{|c|}{ Planting density } \\
\hline & High & Low & $\mathrm{p}$ value \\
\hline $\mathrm{pH}$ & $7.20 \pm 0.46$ & $7.35 \pm 0.38$ & 0.236 \\
\hline $\mathrm{FBD}\left(\mathrm{gdw} \mathrm{cm}^{-3}\right)$ & $0.36 \pm 0.15$ & $0.54 \pm 0.25$ & 0.004 \\
\hline $\mathrm{TP}\left(\mu \mathrm{g} \mathrm{g}^{-1} \mathrm{dw}\right)$ & $425 \pm 203$ & $323 \pm 192$ & 0.08 \\
\hline $\mathrm{TP}\left(\mu \mathrm{g} \mathrm{cm}^{-3}\right)$ & $129 \pm 36$ & $142 \pm 70$ & 0.438 \\
\hline $\mathrm{TN}\left(\mathrm{m} \mathrm{g} \mathrm{g}^{-1} \mathrm{dw}\right)$ & $16.4 \pm 6.7$ & $12.3 \pm 6.5$ & 0.036 \\
\hline $\mathrm{TC}\left(\mathrm{mg} \mathrm{g}^{-1} \mathrm{dw}\right)$ & $221 \pm 85$ & $160 \pm 87$ & 0.017 \\
\hline $\mathrm{C}: \mathrm{N}$ & $15.7 \pm 1.0$ & $14.9 \pm 1.0$ & 0.005 \\
\hline $\mathrm{C}: \mathrm{P}$ & $1441 \pm 337$ & $1360 \pm 319$ & 0.398 \\
\hline $\mathrm{N}: \mathrm{P}$ & $92 \pm 22$ & $91 \pm 20$ & 0.953 \\
\hline $\mathrm{OM}\left(\mathrm{g} \mathrm{g}^{-1} \mathrm{dw}\right)$ & $0.42 \pm 0.18$ & $0.31 \pm 0.19$ & 0.049 \\
\hline & & & \\
\hline
\end{tabular}


Table 8 Independent samples $t$ tests results comparing soil characteristics for $0-10 \mathrm{~cm}$ cores. Values are mean $+/-\mathrm{SD}$. Substrate was evaluated only at high elevations $(n=12)$, elevation was evaluated only in peat substrate $(n=12$ for high, and 23 for low), $\mathrm{n}=24$ for planting density.

\begin{tabular}{|c|c|c|c|c|c|c|c|c|c|}
\hline Parameter (unit) & \multicolumn{2}{|c|}{ Substrate } & $\mathrm{p}$ value & \multicolumn{2}{c|}{ Elevation } & $\mathrm{p}$ value & \multicolumn{2}{c|}{ Planting density } & $\mathrm{p}$ value \\
\hline & Limestone & Peat & & High & Low & & \multicolumn{2}{c|}{ High } & Low \\
\hline $\mathrm{FBD}\left(\mathrm{gdw} \mathrm{cm}^{-3}\right)$ & $0.86 \pm 0.24$ & $0.62 \pm 0.78$ & 0.006 & $0.62 \pm 0.08$ & $0.52 \pm 0.25$ & 0.08 & $0.59 \pm 0.24$ & $0.67 \pm 0.27$ & 0.309 \\
\hline $\mathrm{TP}\left(\mu \mathrm{g} \mathrm{g}^{-1} \mathrm{dw}\right)$ & $153 \pm 71$ & $233 \pm 45$ & 0.003 & $234 \pm 45$ & $309 \pm 156$ & 0.04 & $278 \pm 139$ & $220 \pm 121$ & 0.13 \\
\hline $\mathrm{TP}\left(\mu \mathrm{g} \mathrm{cm}^{-3}\right)$ & $161 \pm 69$ & $249 \pm 46$ & 0.001 & $249 \pm 46$ & $333 \pm 160$ & 0.02 & $304 \pm 143$ & $229 \pm 125$ & 0.063 \\
\hline $\mathrm{TN}\left(\mathrm{mg} \mathrm{g}^{-1} \mathrm{dw}\right)$ & $8.0 \pm 3.9$ & $10.3 \pm 1.8$ & 0.08 & $10.3 \pm 1.8$ & $13.0 \pm 6.2$ & 0.055 & $11.2 \pm 4.7$ & $10.8 \pm 5.7$ & 0.798 \\
\hline $\mathrm{TC}\left(\mathrm{mg} \mathrm{g}^{-1} \mathrm{dw}\right)$ & $100 \pm 48$ & $139 \pm 22$ & 0.017 & $139 \pm 22$ & $170 \pm 81$ & 0.09 & $146 \pm 60$ & $142 \pm 77$ & 0.852 \\
\hline $\mathrm{OM}\left(\mathrm{g} \mathrm{g}^{-1} \mathrm{dw}\right)$ & $0.15 \pm 0.63$ & $0.22 \pm 0.27$ & 0.002 & $0.22 \pm 0.27$ & $0.36 \pm 0.20$ & 0.004 & $0.30 \pm 0.17$ & $0.25 \pm 0.17$ & 0.312 \\
\hline
\end{tabular}

